\title{
Analysis of a High Performance Model Stirling Engine with Compact Porous-sheets Heat Exchangers
}

\author{
Zhigang $\mathrm{Li}^{\mathrm{a}, *}{ }^{\text {, Yoshihiko Haramura }}{ }^{\mathrm{b}}$, Yohei Kato ${ }^{\mathrm{b}}$, Dawei Tang ${ }^{\mathrm{a}}$
}

${ }^{\mathrm{a}}$ Institute of Engineering Thermophysics, Chinese Academy of Sciences, Beijing 100190, China, jager@iet.cn

${ }^{\mathrm{b}}$ Department of Mechanical Engineering, Kanagawa University, Yokohama 221-8686, Japan, haramy01@kanagawa-u.ac.jp

${ }^{*}$ Corresponding author

Affiliation: Institute of Engineering Thermophysics, Chinese Academy of Sciences

Affiliation Address: No. 11, BeiSiHuanXi Road, Beijing 100190, China

Tel: +86-10-82543022

Fax: +86-10-82543022

Email: jager@iet.cn 


\section{Suggest Reviewers}

Ceji Fu

Peking university

cjfu@mech.pku.edu.cn

\section{Yonggang Lv}

Chongqing University

yglv@cqu.edu.cn

Xuehong $\mathrm{Wu}$

Zhengzhou University of Light Industry

wuxh1212@sina.com 


\section{Abstract}

A high performance model Stirling engine, in which the heater, regenerator and cooler as a whole is formed by hundreds of porous metal sheets, is identified for theoretical analysis to facilitate the future scale-up design. The reciprocating flow and heat transfer both in the heat exhcanger and in the full engine is simulated by a dynamic mesh Computational Fluid Dynamics (CFD) method, and is validated by analytical solutions and experimental data. An optimization method is also developed to incorporate the entropy generation caused by flow friction and irreversible heat transfer. The results show that relatively high indicated power of $33.4 \mathrm{~W}$ is obtained, corresponding to a specific power of $1.88 \mathrm{~W} / \mathrm{cm}^{3}$ and a thermal efficiency of $43.9 \%$, which are attributable to the extremely small flow friction loss and excellent heat transfer characteristics in the regular shaped microchannels, as well as to the compact heat exchanger design that significantly reduces the dead volume. Given the same operating conditions, the optimized porous-sheets regenerator has a significantly lower total loss of available work while maintaining even higher thermal effectiveness in comparison with the optimized conventional wire mesh regenerator.

Key Words: Stirling Engine; Regenerator; Porous-sheets; Dynamic Mesh CFD; Optimization 


\section{Introduction}

Stirling engine has a wide application prospect in the power generation field due to its many advantages including adaptability to versatile heat sources, high thermal efficiency and environmental friendliness [1]. However, the relatively low specific power compared to that of the internal combustion engines is still one of the major obstacles hindering its development. So far, extensive research has been done on the regenerator, the central and crucial component of the Stirling engine in order to improve the engine performance [2].

The traditional wire mesh type regenerator is most popularly adopted in Stirling engines due to its huge heat transfer area, high convective heat transfer coefficient brought by the cross flow around numerous cylindrical shaped wires, and low axial thermal conductance. However, there are some inherent disadvantages associated with the wire mesh type regenerator [3], such as: (1) the numerous cylinders in cross flow produce flow separation, wakes, eddies and stagnation zones, resulting in high flow friction and considerable thermal dispersion, a loss mechanism that increases apparent axial conduction, damaging power output and engine efficiency; (2) the wire screens have some randomness in stacking, causing locally non-uniform porosity and flow distribution, which might increase axial conduction and damage its thermodynamic performance; (3) the mesh wires are subject to the impact of high-speed high-frequency oscillating flow during operation, so there exists the possibility of working loose or fiber breakage, thus damaging vital engine components; (4) the wire mesh type regenerator also requires long assembly time which tends to increase their cost.

Theoretically a regenerator with heat transfer surfaces parallel to the oscillating flow has a better performance than wire mesh type regenerators [4]. With the emerging micro-fabrication techniques, properly designed regular-shaped microchannel type regenerator can be fabricated to obtain extremely low flow friction while maintaining high heat transfer. The main features of the regular microchannel type regenerator include: (1) the heat transfer surface is smooth; (2) the flow acceleration rates are controlled; (3) the flow separation is 
minimized; (4) the axial thermal conduction is reduced by interrupting the axial continuity of solid structure, for example, using porous sheets with intermediate gaps or clearance. Other advantages include improved structural durability, no gas leakage or short-circuit loss owing to tight tolerance, low cost for mass production, thus realizing significantly higher comprehensive performance [5].

Researchers in the US has conducted a series research on the regular microchannel type regenerator under the NASA support [6]. The oscillating-flow rig test showed the highest figures of merit ever recorded for any regenerator tested in that rig over its $~ 20$ years of use, demonstrating a shift strongly in the direction of the theoretical performance of ideal parallel-plate regenerators. Numerical projections of engine performance using the “SAGE” code indicated a performance improvement by 6 9\%. Takizawa et al. [7] developed a porous sheet type regenerator with electrically etched holes. Performance test in a 3-kW Stirling engine shows that the engine performance was improved by about 5 to $10 \%$ compared to conventional stacked wire mesh regenerator. A series of engine tests were also done by Matsuguchi et al. [8] to optimize the geometrical parameters of the porous-sheets regenerator.

Nam et al. [9] developed a parallel wire type regenerator. The axial conduction loss is alleviated by wire segmentation, but the number of segmentation is limited for the parallel wires.

Commonly used traditional methods for analyzing and designing Stirling engines include the first, the second and the third order analysis [10]. Recently, Cheng and Yang [11] developed a lumped-mass analytical model to determine the temperature variations in expansion and compression spaces as well as the shaft power output corresponding to different operating speeds. Cheng and Yang [12] also developed a numerical model to predict the transient variations of temperatures, pressures and working fluid masses in the individual working spaces, so as to obtain the thermodynamic behavior of a Stirling engine. Rogdakis et al. [13] analyzed the thermodynamic performance of the Solo Stirling Engine V161 unit using a computer code based on an adiabatic model. Campos et 
al. [14] developed a dimensionless mathematical model, which combines fundamental and empirical correlations, and principles of classical thermodynamics, mass and heat transfer accounting for variable heat transfer coefficients, to simulate the thermodynamic behavior of a Stirling engine. These analysis generally fall into the second order analysis according to Martini [10]'s classification, in which the engine is divided into several (usually five) chambers. Zero- or one- dimensional equations of mass continuity, momentum and energy conservation are solved. Correlations of various flow friction and heat transfer losses are treated as mutually independent and are used to modify the total power output. However, in order to gain a deeper insight into the complex fluid flow and heat transfer processes that occur in the internal gas circuit, and to more accurately predict the engine's performance, a three-dimensional (3D) dynamic mesh computational fluid dynamics (CFD) method is recommended to aid the engine design [15] since it can accommodate complex geometries, complicated boundary conditions and variable physical properties, depends less on empirical correlations that are usually obtained under certain limited experimental conditions. With the rapid development of computing power and CFD tools, the utilization of CFD method in the research and development of Stirling engines [16], thermoacoustic engines [17], pulse tube refrigerators [18] and Stirling regenerator [19] is in an increasing trend in recent years. This method is especially useful in this work since no exact experimental correlations are readily available for the reciprocating flow and heat transfer problem in a hexagonal channel with relatively thick wall.

In this work, a high performance model Stirling engine installed with a compact porous-sheets regenerator that has won the first prize in the $14^{\text {th }}$ Stirling Techno-rally in Japan is identified for theoretical analysis, in order to understand the inherent physical mechanism, and to provide guidance for the future scale-up design. A commercial CFD code FLUENT is utilized to simulate the reciprocating flow and heat transfer in the porous-sheets heat exchanger by a dynamic mesh method, and validated with analytical solutions and experimental results. Then the flow and heat transfer in the entire Stirling engine are numerically simulated using the 3D dynamic mesh CFD 
method. The output power and the thermal efficiency are also obtained. Finally an optimization method is evolved by further taking the total entropy generation into account, and comparis on of comprehensive performance is made between the optimized porous-sheets regenerator and the optimized wire mesh regenerator.

\section{Description of the model Stirling engine installed with a porous-sheets regenerator}

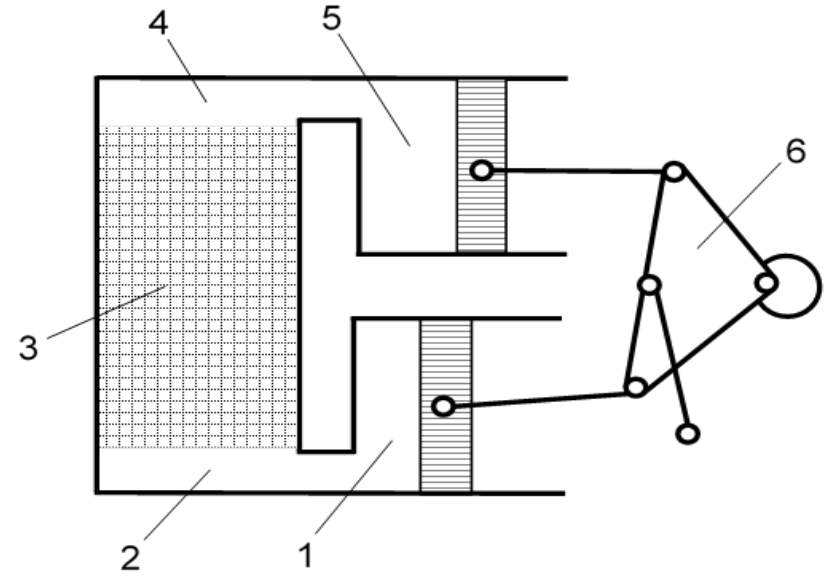

(a)

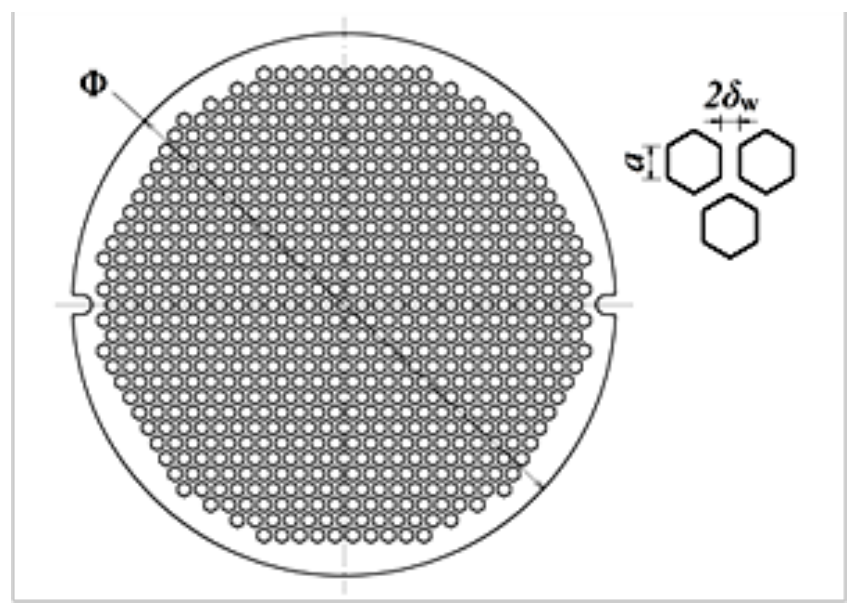

(b)

Fig. 1 Schematics of the model Stirling engine and the porous-sheets heat exchanger [20].

(a) The model Stirling engine. (b) One of the porous sheets. 1 - cold cylinder; 2 - cooling end chamber; 3 porous-sheets heat exchanger; 4 - heating end chamber; 5 - hot cylinder; 6 - Ross drive mechanism

A schematic of the model Stirling engine is shown in Fig. 1(a), the detailed drawings of which can be found at Mr. Fukui's website [20]. The engine is composed of a cold cylinder, a heat exchanger and a hot cylinder arranged in $\alpha$ type configuration. The heat exchanger includes a heating section, a regenerating section and a cooling section, all integrated into the same unit. Two stainless steel end caps form two chambers, connecting the heat exchanger with the cold cylinder and the hot cylinder. The heating section of the heat exchanger together with the hot end cap is heated by a gas burner, and the cooling section together with the cold end cap is cooled by a heat 
pipe connected to a heat sink. A Ross drive mechanism ensures a phase shift of $90^{\circ}$ between the two pistons. The bore and stroke of both cylinders are $32.5 \mathrm{~mm}$ and $21.4 \mathrm{~mm}$. The heat exchanger is constituted by 365 pieces of 0.2-mm-thick, circular shaped, porous, stainless steel sheets, each porous sheet having 685 hexagonal shaped holes arranged as shown in Fig. 1(b), each hole having a side length (a) of $0.4 \mathrm{~mm}$. The porous sheets are laminated and inserted into a cylindrical container with an inner diameter $(\Phi)$ of $28.8 \mathrm{~mm}$, the holes of all sheets being aligned with each other so as to form 685 flow channels for the working gas, each channel having a hexagonal cross section and a length $(L)$ of $73 \mathrm{~mm}$. The engine is charged with helium at atmospheric pressure. The measured rotational speed $(n)$ is $=2,600 \mathrm{rpm}$ under load when the engine is driving a model car.

\section{The reciprocating laminar flow and heat transfer in a single channel}

In order to validate the dynamic mesh method used in the CFD simulation, a single channel model is created as shown in Fig. 2. The channel outer wall is taken along the center planes of the solid skeleton that divide the adjacent channels. The calculation domain includes a single fluid channel with exactly the same shape and size as the actual fluid channel, a solid wall with half the thickness of the real sold material and two cylinders with diameters 3 times that of the hydraulic diameter of the fluid channel.

Some general assumptions are made as follows according to the practical condition,

(1) The working fluid is an ideal gas;

(2) No leakage of working fluid exists;

(3) Adiabatic boundary condition is specified on the outer wall of the engine except at the heating and cooling portions of the heat exchanger;

(4) Sinusoidal movement of the two pistons are specified;

(5) Cyclic steady state with constant frequency is assumed. 


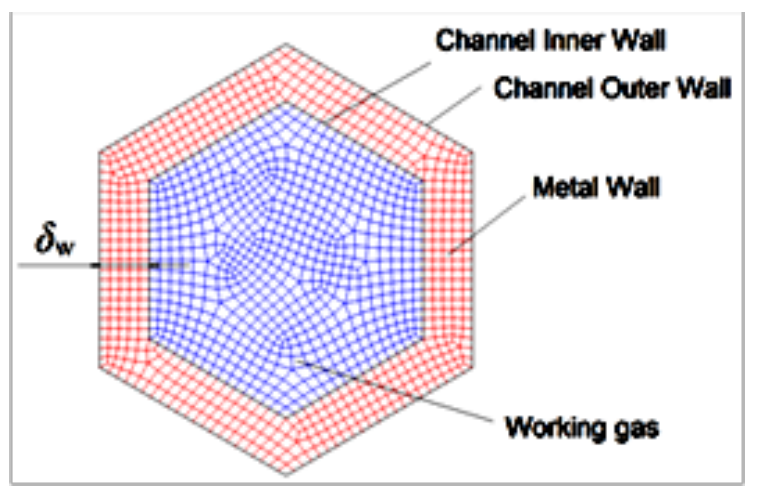

(a)

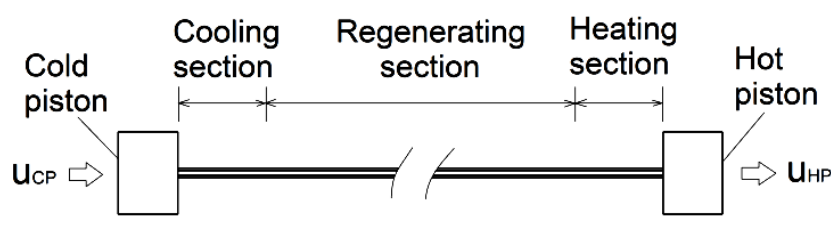

(b)

Fig. 2 Schematics of the single channel model for validation of the dynamic mesh CFD method.

(a) Mesh in the channel cross section. (b) A single channel with two pistons.

\subsection{The reciprocating laminar flow}

The basic equations for transient fluid flow and heat transfer can be found in the user manual of the FLUENT 14.0 software [21], which is omitted in this text. In order to validate the dynamic mesh CFD model by comparing with available analytical solutions for reciprocating laminar pipe flow, the flow field of working gas without compression and expansion, without heating and cooling, is calculated first. Therefore, the energy equation is deactivated in the flow field simulation, and constant thermophysical properties at ambient temperature and atmospheric pressure are set for the working gas.

Zhao [22] has presented a laminar-turbulent transition criteria, $\beta_{\text {cri }}$, for the reciprocating pipe flow as

$$
\beta_{\text {cri क्जmax }}\left(A_{0} \sqrt{\operatorname{Re}}\right)_{\text {cri }}=\left(\begin{array}{ll}
x & \sqrt{\omega / v}
\end{array}\right)_{\text {cri }}
$$

where $A_{0}=x_{\max } / d_{\mathrm{h}}$ is the dimensionless oscillation amplitude of fluid, where $x_{\max }$ is the amplitude of fluid 
displacement, $d_{\mathrm{h}}$ is the hydraulic diameter, $\omega$ is the oscillatory frequency, $\operatorname{Re}_{\omega \mathrm{h}}=\omega d^{2} / v$ is the kinetic Reynolds number, where $v$ is the kinematic viscosity of fluid. Since the parameter $\beta$ of the reciprocating channel flow in question is only 93.0, far below the critical value $\beta_{\text {cri }}$ of 761 presented by Zhao [22], the flow is treated as laminar in the calculation.

A "layering" scheme is used for the dynamic mesh method, in which the cell quantity is varying and the cell shape is deforming with time in both cylinders. A "rigid body" motion is specified to each of the two piston walls with the following velocity profile by using a compiled User Defined Function (UDF).

$$
U=U_{\max } \sin \omega t
$$

where $U$ and $U_{\max }$ are the transient speed and the maximum piston speed. $U_{\max }$ is determined by multiplying the real piston speed with the cross-sectional area ratio of the piston to the flow channel, to ensure that the flow velocity in the channel equals to the real flow velocity. All the other boundaries are set as hydrodynamically no-slip and thermally adiabatic walls. An initial gauge pressure of $0 \mathrm{~Pa}$ is applied to the whole flow field.

The PISO scheme is used for the pressure - velocity coupling because of its high efficiency in transient flow simulation. A constant time step corresponding to a crank angle of $1^{\circ}$ is adopted during the simulation. A residual of $1 \times 10^{-4}$ for the continuity equation and the momentum equations in 3 directions is set as the convergence criteria. The cross-sectional average pressure at the channel inlet and outlet and the area-weighted average shear stress at the channel inner wall are monitored during the simulation.

A grid independence test shows that when the initial mesh is created with 1.7 million cells, the resulting pressure - time curve varies less than $0.1 \%$ if further increasing the initial cell quantity.

After about 10 cycles of iteration, the pressure amplitude varies less than $0.1 \%$ relative to that of the previous cycle, so the cyclic steady state can be considered as having been reached. Then the calculation results of flow friction loss and total pressure drop at the cyclic steady state are compared with the following analytical 
solution for fully developed laminar reciprocating flow in a circular pipe derived by Uchida [23] and experimentally validated by Zhao [24].

$$
c_{\mathrm{f}, \infty}=\frac{32 F_{\omega}}{A_{0}} \sin \left(\phi+\phi_{1}\right)
$$

where $\phi$ is the crank angle, and $\phi_{1}$ is the phase shift (in degrees) between the cross-sectional mean velocity and the wall shearstress, $c_{\mathrm{f}, \mathrm{o}}$ is the frictional coefficient for fully developed flow defined by

$$
C_{\mathrm{f}, \infty}(t)=\frac{\tau_{\mathrm{w}}(t)}{\frac{1}{2} \rho u_{\text {max }}^{2}}=\frac{-\mu(\nabla \vec{V})_{\mathrm{w}}}{\frac{1}{2} \rho u_{\text {max }}^{2}}
$$

where $t$ is time, $\tau_{\mathrm{w}}$ is time varying area weighted average shear stress at the channel inner wall, $\rho$ is the fluid density, $u_{\max }$ is the maximum cross-sectional mean velocity of the cyclic flow in the channel, $\mu$ is the dynamic viscosity of the fluid, $\vec{V}$ is the velocity vector, $F_{\omega}$ is calculated by

$$
F_{\omega}=\frac{\sqrt{C_{1}^{2}+C_{2}^{2}}}{16 \sqrt{\left(\alpha-2 C_{1}\right)^{2}+4 C_{2}^{2}}}
$$

$\phi_{1}$ is calculated by

$$
\phi_{1}=\tan ^{-1}\left(\frac{\alpha-2 C_{1}}{2 C_{2}}\right)-\tan ^{-1}\left(\frac{C_{2}}{C_{1}}\right)
$$

where $\alpha$ is the Womersley number defined by $\alpha=\sqrt{\mathrm{Re}_{\omega}} / 2$, and $C_{1}, C_{2}$ are constants given by

$$
\begin{aligned}
& C_{1}=\frac{\text { ber } \alpha \text { bei' }^{\prime} \alpha-\text { bei } \alpha \text { ber }^{\prime} \alpha}{\operatorname{ber}^{2} \alpha+\text { bei }^{2} \alpha} \\
& C_{2}=\frac{{\text { ber } \alpha \text { ber }^{\prime} \alpha+\text { bei } \alpha \text { bei }^{\prime} \alpha}_{\operatorname{ber}^{2} \alpha+\text { bei }^{2} \alpha}}{\text { a }^{2}}
\end{aligned}
$$

where ber' $\alpha=d(\operatorname{ber} \alpha) / d \alpha$ and bei' $\alpha=d($ bei $\alpha) / d \alpha$.

The comparis on of wall shear stress and total pressure drop with analytical solutions under different $R e_{\omega}$ are shown in Fig. 3, in which the analytical total pressure drop is calculated by

$$
\Delta p=\rho L \frac{d u_{\mathrm{m}}}{d t}+4 \tau_{\mathrm{w}} \frac{L}{d_{\mathrm{h}}}
$$




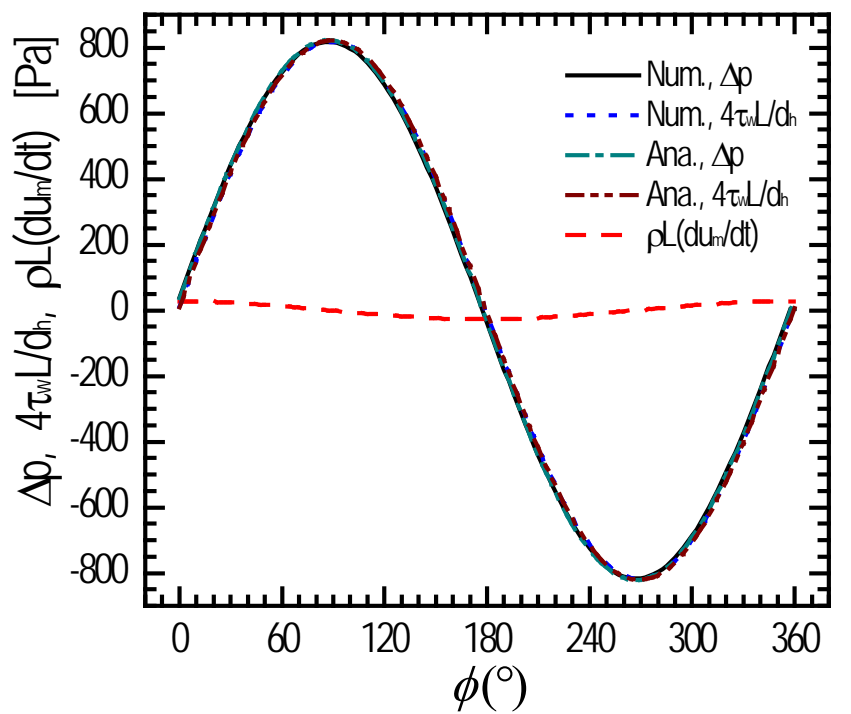

(a)

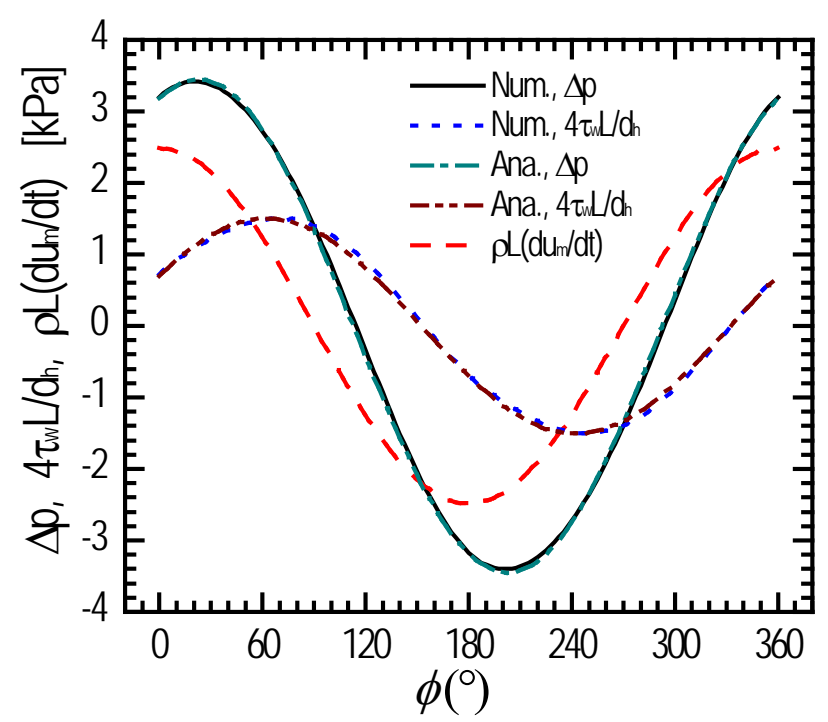

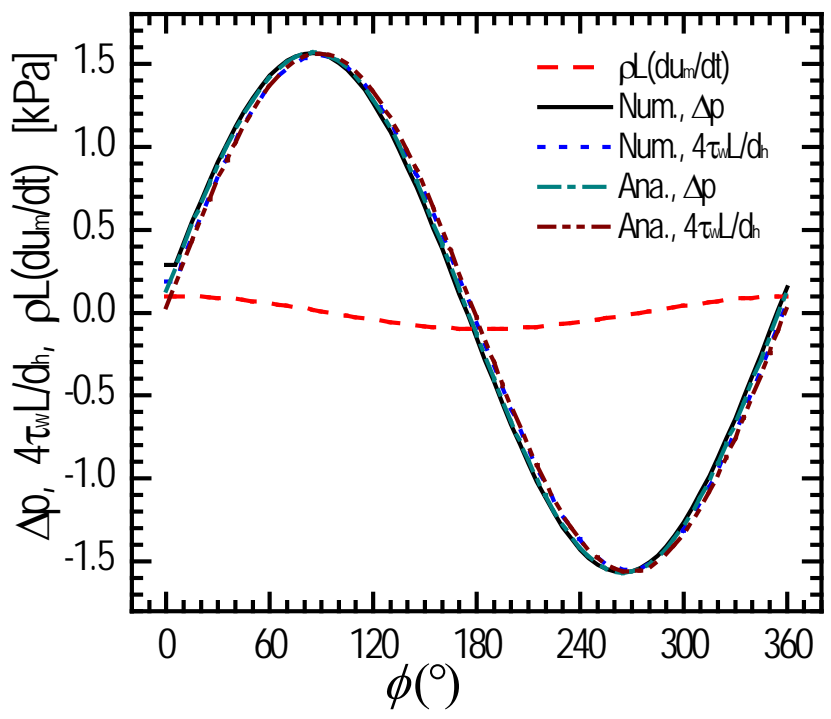

(b)

(c)

Fig. 3 Validation of the dynamic mesh model.

(a) $\operatorname{Re}_{\omega}=1.07$; (b) $\operatorname{Re}_{\omega}=2.14$; (c) $\operatorname{Re}_{\omega}=71.9$ Num. - Numerical; Ana.- Analytical; $\Delta p$ - Total pressure drop; $4 \tau_{\mathrm{w}} L / d_{\mathrm{h}}-$ Frictional loss component; $\rho L\left(\mathrm{~d} u_{\mathrm{m}} / \mathrm{d} t\right)$ - temporal acceleration component.

Good agreement is found between the analytical solution for fully developed flow and the dynamic CFD results with a maximum deviation of $2.37 \%$, which can be attributed to the entrance effects when the fluid enters 
and exits the channel, so the analytical solution is to be integrated into the CFD simulation of the overall engine in the later sections to reduce the computational cost. The parameters $F_{\omega}$ and $\phi_{1}$ versus $\operatorname{Re}_{\omega}$ in the analytical expression are plotted in Fig. 4(a), and the cyclically averaged frictional coefficient is plotted in Fig. 4(b) for the ease of use in the investigation of the model Stirling engine, where $C_{\mathrm{f}, \infty, a v e}$ is given by

$$
C_{\mathrm{f}, \infty, \mathrm{ave}}=\frac{64 F_{\omega}}{\pi A_{0}}
$$

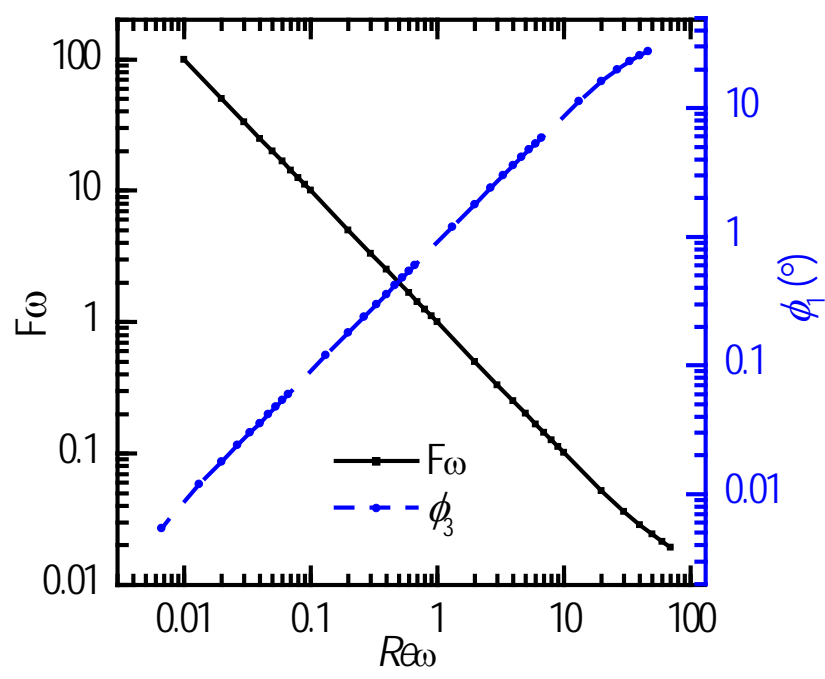

(a)

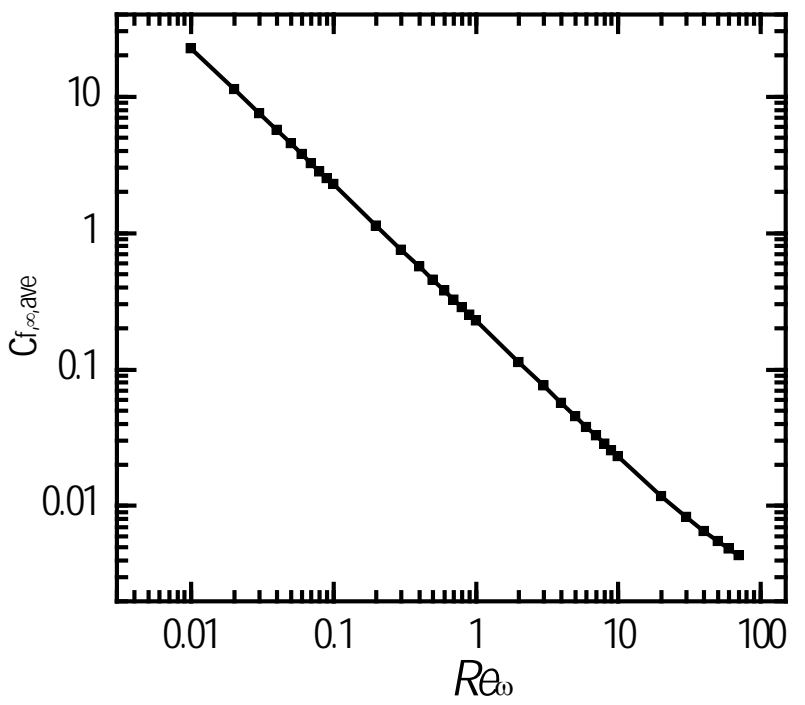

(b)

Fig. 4 Analytical solution.

(a) Parameters $F_{\omega}$ and $\phi_{3}$ (in degree) in the analytical expression. (b) $C_{\mathrm{f}, \infty, a v e}$

\subsection{The conjugate he at transfer with limited temperature difference}

Still referring to Fig. 2, in order to evaluate the conjugate heat transfer characteristics of the heat exchanger, the heat conduction in the solid substrate and the convective heat transfer in the reciprocating flow are simultaneously solved. Two types of thermal boundary conditions are applied to the outer wall of the heating section: 
(1) Constant heat flux of $5,000 \mathrm{~W} / \mathrm{m}^{2}$, corresponding to such cases as heating by concentrated solar irradiation;

(2) Constant temperature of 923K, corresponding to such cases as heating by heat pipe.

In both cases, a constant temperature of $350 \mathrm{~K}$ is set at the outer wall of the cooling section, and an adiabatic boundary condition is applied to the outer wall of the regenerating section. All the inner walls of the 3 channel sections are set as "Coupled walls", i.e., hydrodynamically non-slip wall satisfying the temperature continuity and heat flux continuity conditions at both sides of the wall, which are described as

$$
\begin{aligned}
& \left(T_{\mathrm{s}}\right)_{\mathrm{w}}=\left(T_{\mathrm{f}}\right)_{\mathrm{w}} \\
& \left(q_{\mathrm{s}}\right)_{\mathrm{w}}=\left(q_{\mathrm{f}}\right)_{\mathrm{w}}
\end{aligned}
$$

The energy equation is activated, and the idea gas law is adopted for the helium density. The thermal conductivity and the dynamic viscosity of the fluid, the thermal conductivity and the specific heat capacity of the stainless steel substrate are all set as piecewise linear functions of temperature. The dynamic mesh and the moving piston wall settings are the same as the previous settings for the flow field simulation. All the other boundaries are set as hydrodynamically non-slip and thermally adiabatic walls. An initial condition of zero gauge pressure is applied to the whole flow field.

A residual of $1 \times 10^{-4}$ for the continuity equation and the momentum equations in 3 directions, and a residual of $1 \times 10^{-7}$ for the energy equation are set as the convergence criteria. The other solver settings are the same with the previous setting for fluid flow simulation. The local convective heat transfer coefficients are obtained by data post-processing for a specific time step using the following definition.

$$
h_{x}=\left|\frac{q_{\mathrm{wi}}(x)}{T_{\mathrm{wi}}(x)-T_{\mathrm{b}}(x)}\right|
$$

where $q_{\mathrm{wi}}(x)$ is the local average heat flux through the inner channel wall calculated by 


$$
q_{\mathrm{wi}}(x)=\frac{1}{P} \int_{\Gamma} q_{\mathrm{wi}}(x, y, z) d l
$$

where $\Gamma$ is the hexagonal boundary curve of the channel cross section, and $P$ is the corresponding curve perimeter; $T_{\mathrm{wi}}(x)$ is the local average temperature of the inner channel wall calculated by

$$
T_{\mathrm{wi}}(x)=\frac{1}{P} \int_{\Gamma} T_{\mathrm{wi}}(x, y, z) d l
$$

and $T_{\mathrm{b}}(x)$ is the local mixed mean temperature defined by

$$
T_{\mathrm{b}}(x)=\frac{\int_{\mathrm{A}_{\mathrm{e}}} \rho c_{\mathrm{p}} T(x, y, z) u(x, y, z) d A}{\int_{\mathrm{A}_{\mathrm{e}}} \rho c_{\mathrm{p}} u(x, y, z) d A} \approx \frac{\int_{\mathrm{A}_{\mathrm{e}}} T(x, y, z) u(x, y, z) d A}{\int_{\mathrm{A}_{\mathrm{e}}} u(x, y, z) d A}
$$

where $\rho$ and $c_{\mathrm{p}}$ are considered as functions of longitudinal location only, and are treated as constant within a local cross section since the temperature variation within a cross section is negligible compared to the longitudinal variation.

The local Nusselt number is defined by

$$
N u_{x}=\frac{h_{x} d_{\mathrm{h}}}{k_{\mathrm{f}}(x)}
$$

where $k_{\mathrm{f}}(x)$ is the local thermal conductivity of the working gas.

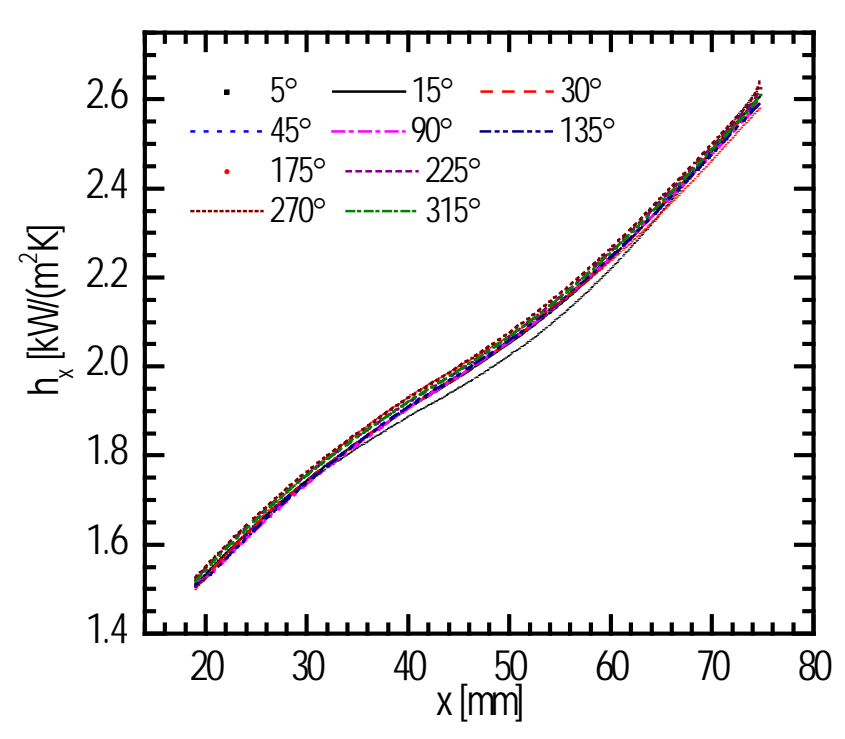

(a)

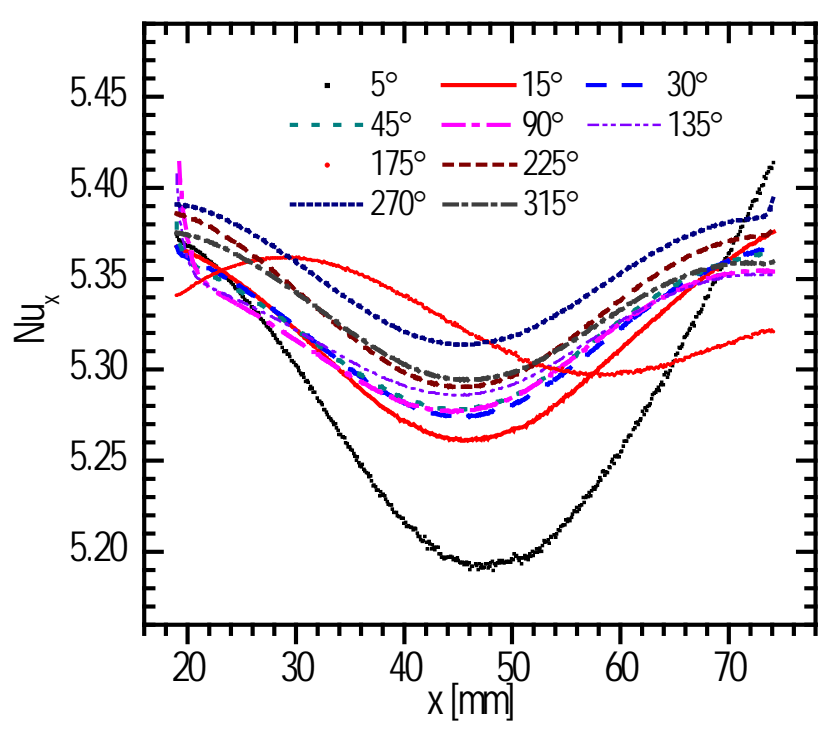

(b) 


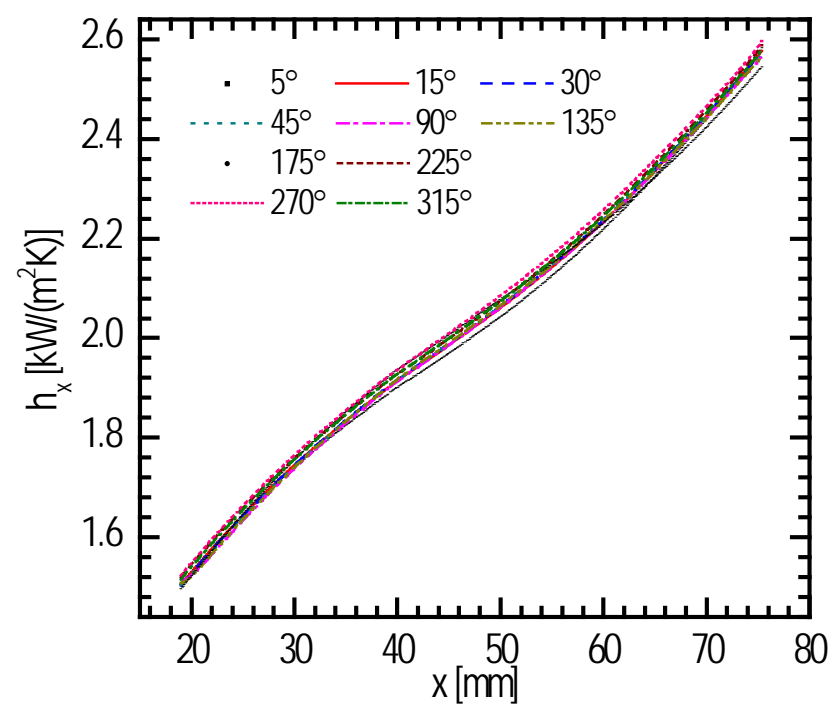

(c)

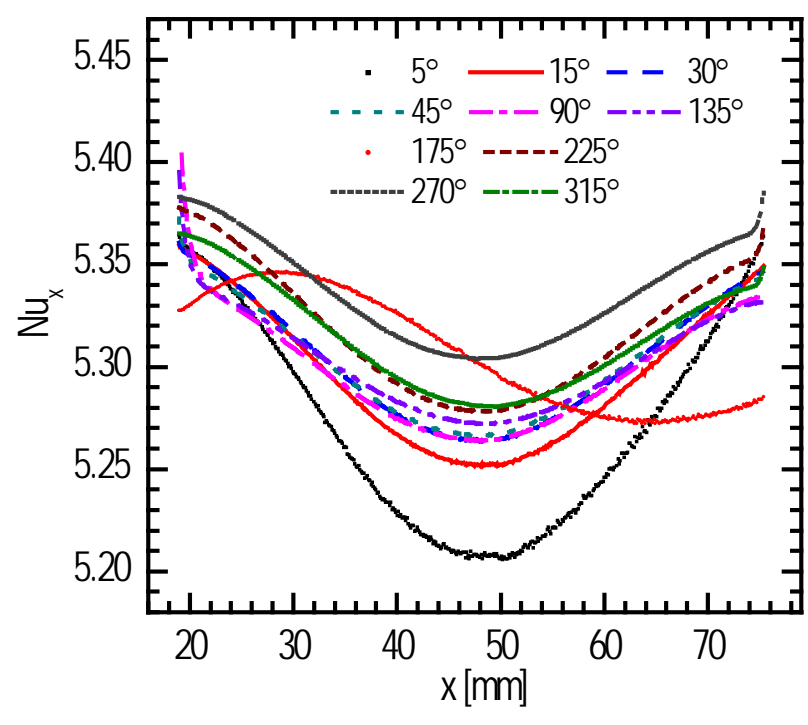

(d)

Fig. 5 Heat transfer characteristics of the porous-sheets regenerator under different boundary conditions at the heater wall.

(a) $h_{x}(\phi)$, Constant temperature; (b) $N u_{x}(\phi)$, Constant temperature; (c) $h_{x}(\phi)$, Constant heat flux; (d) $N u_{x}(\phi)$, Constant heat flux.

The spatial and temporal distributions of $h_{x}$ and $N u_{x}$ in the regenerator section under the two types of thermal boundary condition are calculated and illustrated in Fig. 5. It is interesting to observe that in both cases, although the local heat transfer coefficient varies largely and almost linearly in the longitudinal direction due to the large difference of gas thermal conductivity at different temperature, the local Nusselt number varies not much (less than 3.7\%) and shows a valley-shaped pattern in the longitudinal direction, which might be caused by the influence of entrance and exit effects at both ends. It is also observed that both the heat transfer coefficients and the Nusselt number varies little (less than 1.4\%) with crank angles except at some crank angles when the fluid velocity approaches zero and the data uncertainty might be increased, for examples, at $5^{\circ}$ and $175^{\circ}$. There is insignificant difference between the two types of boundary conditions when the convective heat transfer coefficient and the 
Nusselt number are concerned, which may indicate that the influence of different thermal boundary conditions at the heating section is not easy to be transferred to the regenerator section. It is also interesting to find that the calculated Nusselt number in both cases is somewhat higher than the analytical solutions for fully developed unidirectional laminar flow in a long pipe with hexagonal shaped cross section, which has a value of 4.00 for the uniform wall heat flux boundary condition, and 3.34 for the uniform wall temperature boundary condition [25]. This might be explained by the difference in the flow and thermal conditions. The reciprocating flow might disturb the boundary layer and reduce its thickness, which is favorable for enhancing the convective heat transfer. On the other hand, the adiabatic boundary condition at the outer channel wall is different with either the constant wall heat flux boundary condition or the constant wall temperature boundary condition, and the limited heat capacity of the solid substrate material might be a major limit for the heat transfer.

Based on the calculated results of heat transfer characteristics as shown above, a space-cycle averaged Nusselt number defined as follows might be appropriate for the engine design in most cases.

$$
N u_{\text {ave }}=\frac{1}{2 \pi L} \int_{0}^{2 \pi} \int_{0}^{L} N u_{x}(\phi) d x d \phi
$$

In this paper, the calculated $N u_{\text {ave }}$ values are 5.33 for the case of constant heater wall heat flux, and 5.31 for the case of constant heater wall temperature, respectively.

\section{Dynamic mesh CFD simulation of the entire engine}

\subsection{Validation of the porous media sub-model}

Complete meshing of the solid substrate and fluid in the heat exchanger portion is not suitable for engineering application or even impossible due to the extremely high computational cost. In order to significantly increase the computational efficiency for the full engine model, the porous media sub-model is used to integrate the analytical solutions of reciprocating laminar flow into the heat exchanger portion of the Stirling engine. The 
determination of the parameters in the porous media sub-model is as follows.

Let

$$
u_{m}=u_{\max } \sin \phi
$$

where $u_{\mathrm{m}}$ is the cyclically averaged cross-sectional mean fluid velocity in the exchanger channel.

The analytical solution for the frictional loss per unit length in the channels is given by

$$
-4 \frac{\tau_{\mathrm{w \omega}}}{d_{\mathrm{h}}}=-\frac{64 F}{x_{\max }} \rho u_{\max }^{2} \sin \left(\phi+\phi_{1}\right)
$$

The momentum sink term in the porous media model [21] is described by

$$
S_{\mathrm{i}}=-\left[\frac{\mu}{\alpha}\left(\varepsilon u_{\mathrm{m}}\right)+C_{3} \frac{1}{2} \rho\left(\varepsilon u_{\mathrm{m}}\right)^{2}\right]
$$

Compare the above two formulae, let

$$
\begin{gathered}
\frac{64 F_{\omega}}{x_{\max }} \rho u_{\max }^{2} \frac{2}{\pi} \int_{0}^{\frac{\pi}{2}} \sin \left(\phi+\phi_{1}\right) d\left(\phi+\phi_{1}\right)=\frac{\mu}{\alpha}\left(\varepsilon u_{\mathrm{m}}\right) \\
\mathrm{C}_{3}=0
\end{gathered}
$$

where the regenerator porosity $\varepsilon$ is calculated by $\varepsilon=n A_{\mathrm{ch}} / A_{\mathrm{reg}}$, where $n$ is the total number of channels, $A_{\mathrm{ch}}$ is the cross-sectional area of a single channel, and $A_{\text {reg }}$ is the frontal area of the regenerator. Then the viscous friction coefficient is obtained as

$$
\frac{1}{\alpha}=\frac{32 \omega \rho F_{\omega}}{\mu \varepsilon}
$$

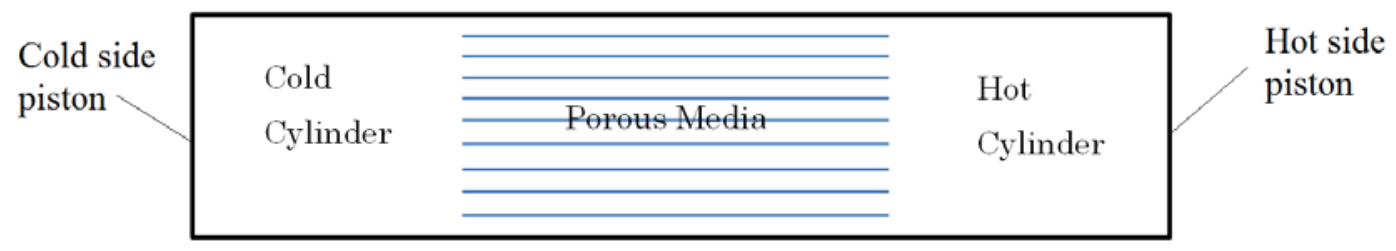

(a) 


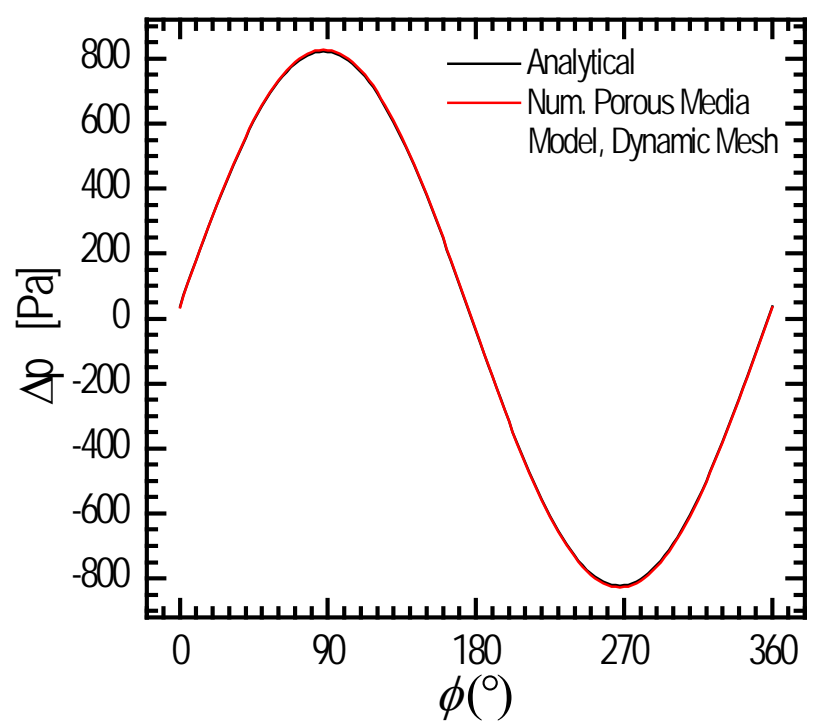

(b)

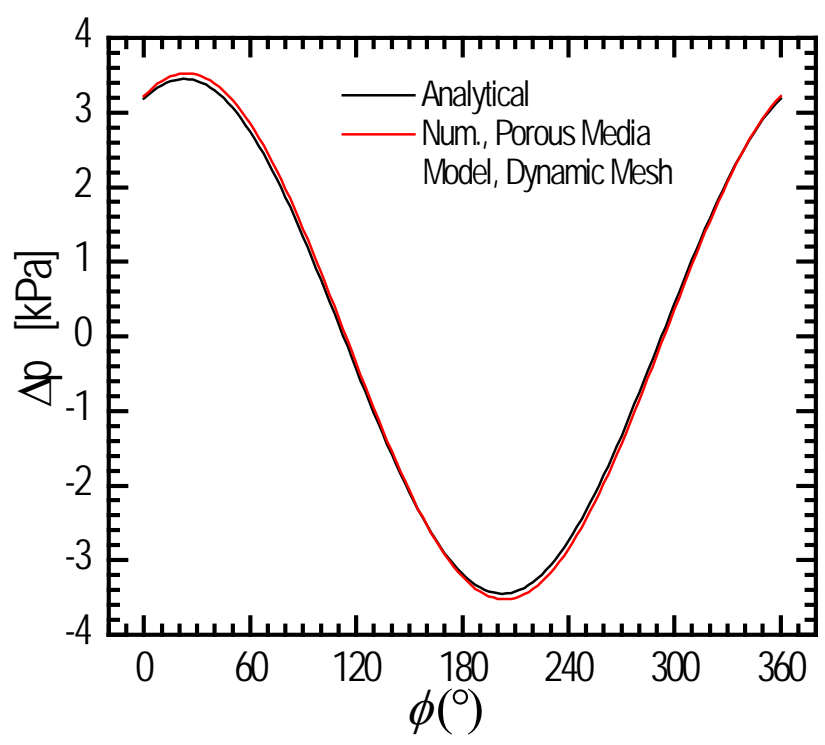

(c)

Fig. 6 Validation of the porous media model.

(a) The test calculation model used for validating the porous media model; (b) At $2600 \mathrm{rpm}, 1 \mathrm{~atm}, 300 \mathrm{~K}$

$$
\left(\operatorname{Re}_{\omega}=1.07, \frac{1}{\alpha}=1.2427 \times 10^{8} \frac{1}{\mathrm{~m}^{2}}\right) ;\left(\text { c) At } 3500 \mathrm{rpm}, 50 \mathrm{~atm}, 300 \mathrm{~K}\left(\mathrm{Re}_{\omega}=71.9, \frac{1}{\alpha}=1.689 \times 10^{8} \frac{1}{\mathrm{~m}^{2}}\right)\right.
$$

A test calculation model as shown in Fig. 6(a) including a porous media portion and two cylinder portions is designed to validate the porous media model. The porous media portion has the same dimension with the real heat exchanger, and the frictional coefficient and porosity parameters are determined according to the above method. A sinusoidal movement is specified on each of the two pistons without phase shift. The other settings are similar to that of the previous sections. The simulation results at ambient temperature under low and high kinetic Reynolds numbers are shown in Figs. 6(b) and 6(c). At the low $\mathrm{Re}_{\omega}$ of 1.07, the deviation of the porous media model result from the analytical solution is less than $0.6 \%$, while with the increasing of $\operatorname{Re}_{\omega}$, the difference between the porous media model result and the analytical solution increases, reaching $2.9 \%$ at a $\operatorname{Re}_{\omega}$ of 71.9 , which might be due to the simplification by neglecting the inertial loss term as expressed in Eq. (17b). Since the $\mathrm{Re}_{\omega}$ value in the real model Stirling engine is close to 1.0, the neglect of inertial loss term is acceptable in the porous media model. 


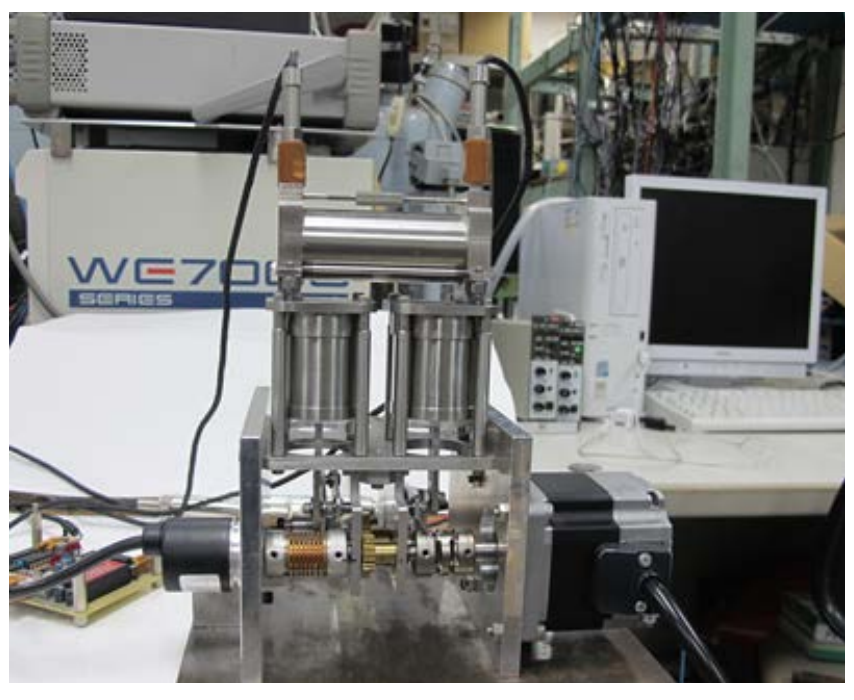

(a)

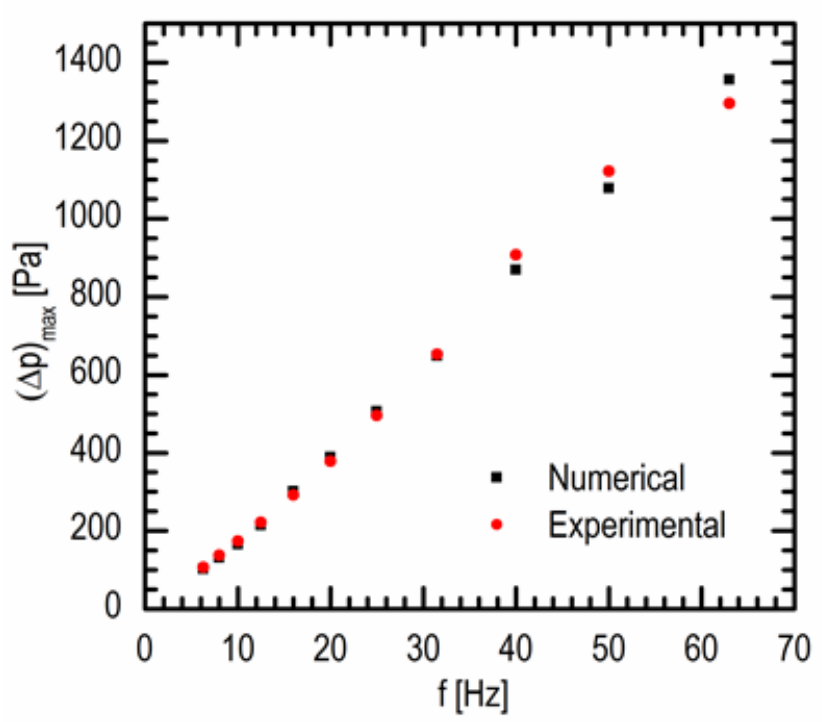

(b)

Fig. 7 Validation of the CFD model with experiment.

(a) Experimental setup; (b) Comparison of pressure drop between numerical result and experimental data.

In order to validate the dynamic CFD method for the full engine model, experiment is conducted on the real model Stirling engine to measure the transient pressure drop through the porous-sheets heat exchanger. The phase shift between the two pistons is adjusted to $180^{\circ}$ to exclude the effect of compression and expansion. As shown in Fig. 7(a), two semiconductor pressure transducers (JTEKT PMS-5M-2-50K) are inserted into the two end chambers of the porous-sheets heat exchanger. The signal is recorded by a data acquisition system(Yokogawa WE7000). The phase angle and rotating frequency is measured by an angular encoder, which is controlled by a digital signal processor. For each frequency value, after waiting for $30 \sim 60 \mathrm{~s}$ to reach a steady state, data are sampled and stored for 20 revolutions. Air is selected as the working fluid in the experiment and the working frequency ranges from 6.3 to $63 \mathrm{~Hz}$. The Pressure drop signal is fitted to a sinusoidal form as

$$
\Delta p=(\Delta p)_{\max } \sin \left(\phi+\phi_{2}\right)
$$

Then numerical simulation is conducted using the dynamic mesh CFD method incorporating the porous 
media model. The geometric parameters, working fluid and rotating frequency are assumed all the same as measured values. The pressure amplitude $(\Delta p)_{\max }$ at the corresponding position of the pressure transducer is extracted and plotted against rotating frequency in Fig. 7(b) in comparison with the experimental data. The experimental error mainly comes from the inaccuracy of crank angle and pressure measurement. The uncertainty of the crank angle is estimated to be $\pm 0.25^{\circ}$ fro $\mathrm{m}$ the accuracy limitation of the orig in setting and the sensitivity of the rotary encoder. The inaccuracy of the pressure transducer is less than $\pm 0.3 \%$ of the pressure amplitude. The simulation results agree quite well with the experimental data with a maximum relative error of $4.6 \%$.

\subsection{Flow with compression and expansion under ambient tempe rature}

The computational domain for the full engine model includes two cylinders, the heat exchanger, the cooling end chamber that connects the cold cylinder with the heat exchanger, and the hot end chamber that connects the hot cylinder with the heat exchanger. The following motion speed functions are specified for the cold side piston and the hot side piston by UDF to take into account the expansion and compression effects in the real engine.

$$
\begin{gathered}
U_{\mathrm{cp}}=U_{\text {max }} \sin \omega t \\
U_{\mathrm{hp}}=U_{\text {max }} \sin \left(\omega t+\frac{\pi}{2}\right)
\end{gathered}
$$

A floating operating pressure is used to reduce the truncation error in such a closed system with compression and expansion. Ideal gas law is used for the gas density, but the temperature of all cell zones is fixed to a constant value of $300 \mathrm{~K}$ in the cold state simulation in order to study the effects of compression and expansion. The settings for other thermophysical properties, boundary conditions and the solver settings are similar to that of the dynamic mesh simulations in the previous sections. 

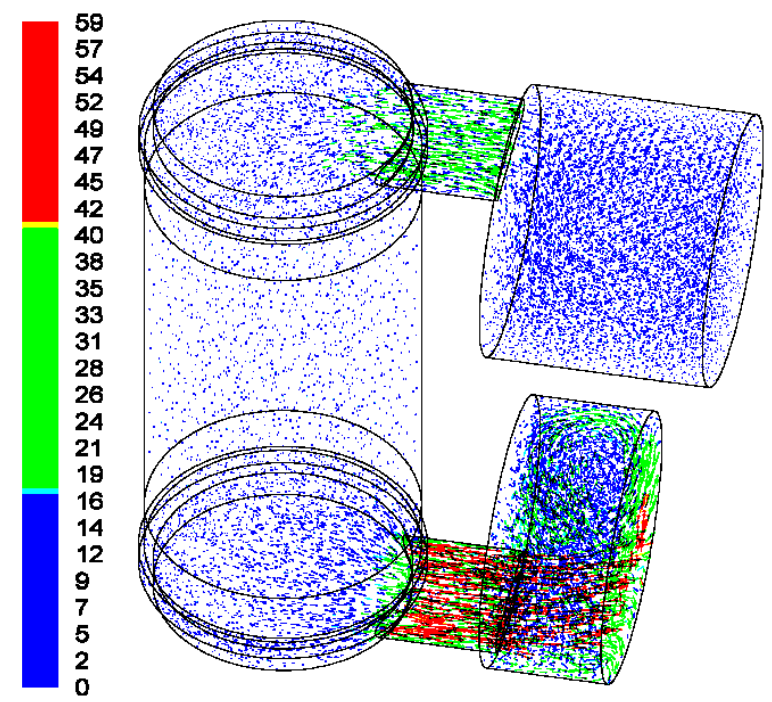

(a)

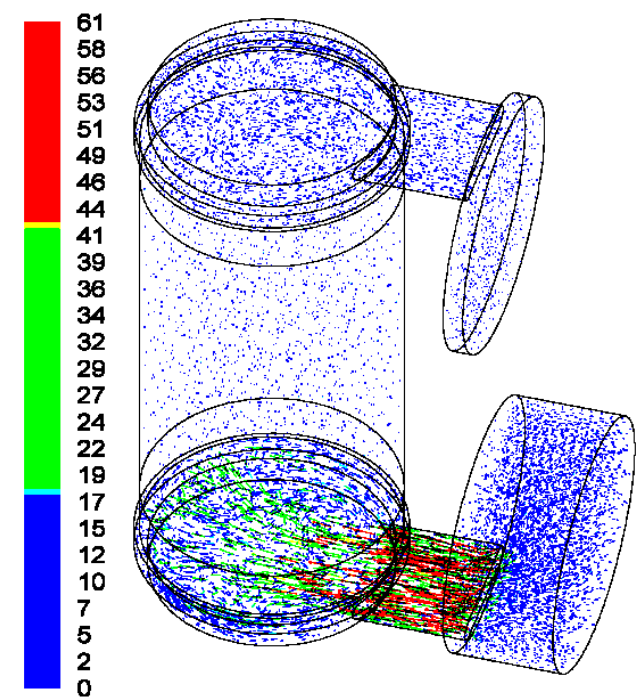

(c)

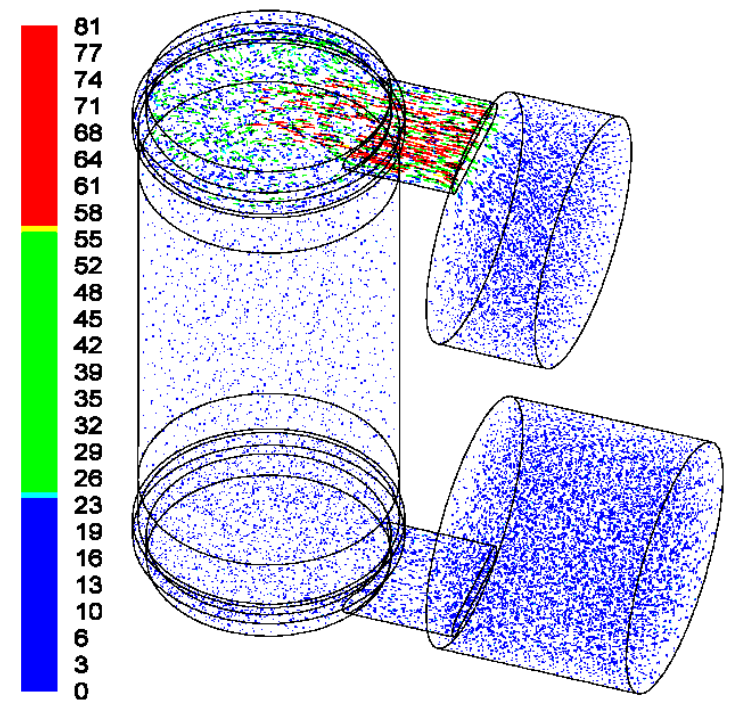

(b)

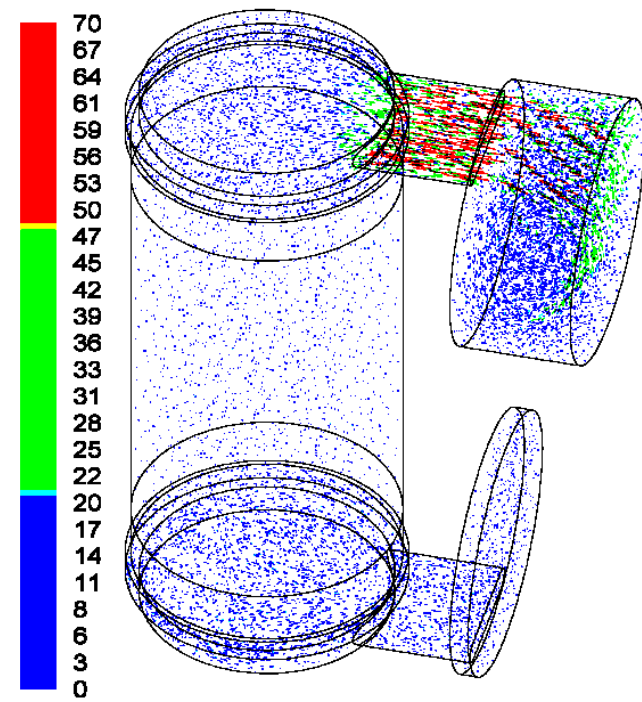

(d)

Fig. 8 Velocity vectors.

(a) $\phi=0^{\circ}$; (b) $\phi=90^{\circ}$; (c) $\phi=180^{\circ}$; (d) $\phi=270^{\circ}$.

Figure 8 shows the 3D velocity vectors at different crank angles. It can be observed that the flow distribution in the heat exchanger is quite uniform due to relatively low pressure drop in the connecting chambers and cylinders compared with that in the heat exchanger. 


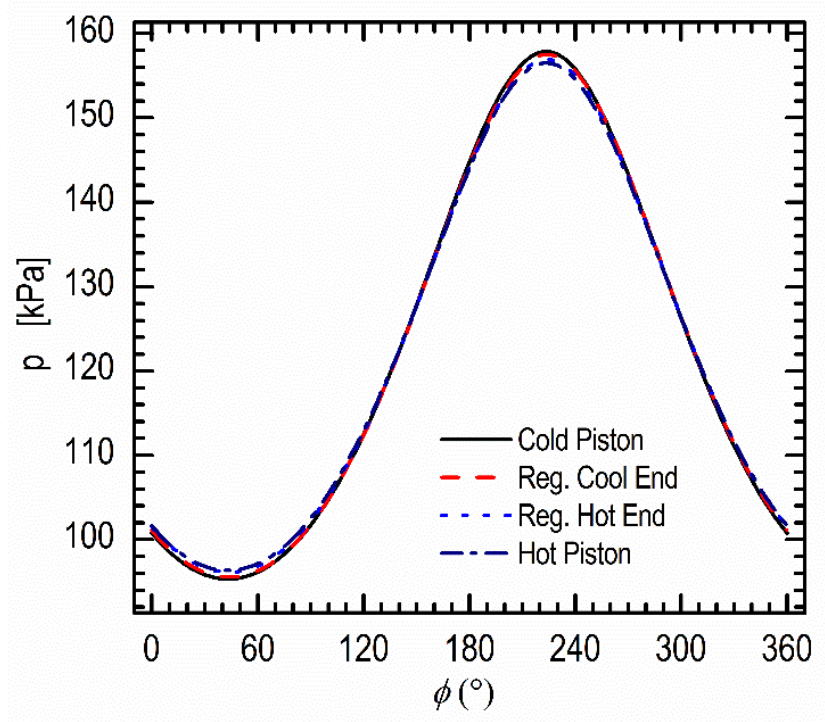

Fig. 9 Pressure variation at different locations versus crank angle in a cycle with compression and expansion at the constant temperature of $300 \mathrm{~K}$.

Figure 9 shows the pressure variation at different locations of the engine with time when a cyclic steady state is reached. The pressure difference among different locations can be attributed to the internal flow resistance of the gas passage. The simulation result of pressure magnitude is compared with the ideal gas law, and the deviation is within $1.2 \%$.

\subsection{Flow with compression, expansion, heating and cooling}

To better characterize the heat transfer between the working gas and the solid substrate with limited temperature difference and limited heat capacity, a non-thermo-equilibrium model is used for the porous media portion. This model is based on a "dual cell” approach, which involves a second solid cell zone that overlaps, i.e., spatially coincident with, the porous fluid zone. The two zones are solved simultaneously and this solid zone only interacts with the fluid with regard to heat transfer. The conservation equation solved for the fluid and solid zones can be found in the FLUENT user manual [21], which is omitted here. A constant Nusselt number of 5.3 and a specific heat exchange area of $2.6699 \times 10^{3} \mathrm{~m}^{2} / \mathrm{m}^{3}$ are adopted for the non-thermo-equilibrium porous media model. 
The flame is concentrated upon the heating section of the heat exchanger assembly, and the combustion gas is directed to the hot cylinder, so the hot end of heat exchanger assembly, the hot cylinder and the connecting chamber between them are all exposed to hot combustion gas environment, then the combustion gas functions as fine thermal insulator to prevent heat loss, therefore in the CFD modeling it is assumed that heat enters and leaves the system only through the heating and cooling sections of the heat exchanger, while all the other boundaries are treated as adiabatic walls. The outer surface of the heating portion is assigned a constant heating power, $Q_{\text {in }}$, of 76.0 W, and the outer surface of the cooling portion is assigned a constant temperature of $330 \mathrm{~K}$ as the thermal boundary conditions. The initial temperature field is obtained by solving a steady state energy equation before the transient calculation begins, and applied to the overall calculation domain as an initial thermal condition. The initial absolute pressure is set to a value of $1.3 \times 10^{5} \mathrm{~Pa}$. The settings for the thermophysical properties, the dynamic mesh, the other boundary conditions and the solver are similar to that of Section 4.2.

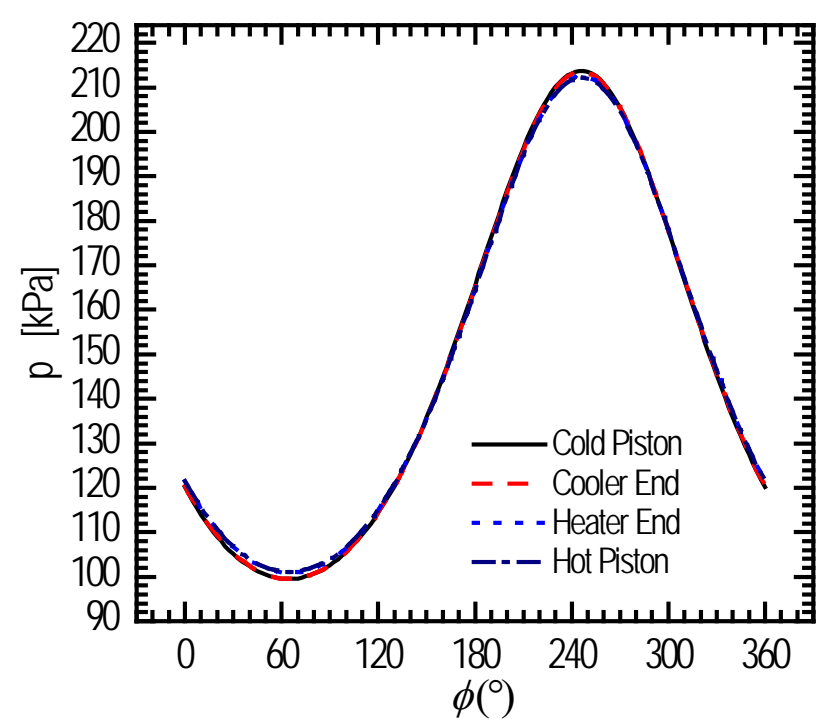

(a)

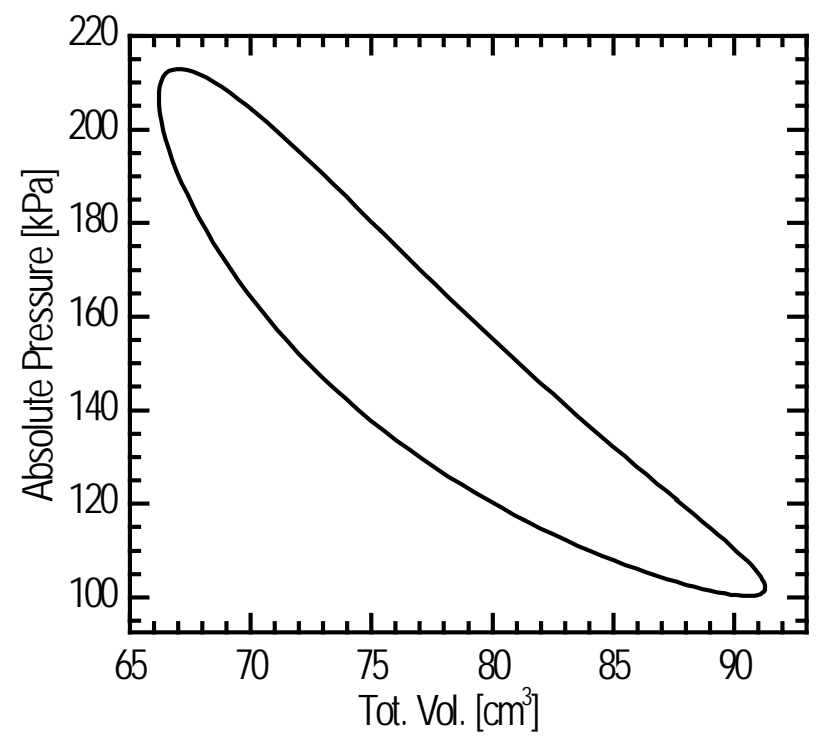

(b)

Fig. 10 Pressure variation with compression and expansion with heating and cooling.

(a) Pressure variation at different locations versus crank angle in a cycle. (b) $p^{-}-v$ diagram. 
Figure 10(a) shows the pressure variation at different locations of the working space against time when a cyclic steady state is reached. The pressure difference among different locations can also be attributed to the internal flow resistance of the gas passage. The area-weighted pressure of working gas adjacent to the two pistons is plotted against the variation of total volume, and is shown in Fig. 10(b). The main specifications and calculated performance of the model Stirling engine are shown in Table 1. An indicated power of 33.4W is obtained by integrating the $p-V$ diagram, corresponding to a specific power of $1.88 \mathrm{~W} / \mathrm{cm}^{3}$ based on the swept volume of the expansion cylinder, and an indicated thermal efficiency $\left(\eta=W / Q_{\text {in }}\right)$ of $43.9 \%$, which is considered high performance among model Stirling engines under low operating pressure.

Table 1 Engine specifications and calculated performance data

\begin{tabular}{|c|r|l|r|}
\hline Bore $\times$ Stroke $(\mathrm{mm})$ & & Gas Mean Temperature $(\mathrm{K})$ & \\
Expansion Cylinder & $32.5 \times 21.4$ & $\begin{array}{l}\text { Heating End } \\
\text { Cooling End }\end{array}$ & 367 \\
Compression Cylinder & $32.5 \times 21.4$ & & 1020 \\
\hline Dead Volume $\left(\mathrm{cm}^{3}\right)$ & 25.50 & Rotating Speed $(\mathrm{rpm})$ & 2600 \\
\cline { 3 - 4 } Heating end chamber & 1.72 & Pressure Ratio $\left(\mathrm{P}_{\max } / \mathrm{P}_{\min }\right)$ & 2.15 \\
\cline { 3 - 4 } Heat exchanger & 20.78 & Compression Ratio $\left(\mathrm{V}_{\max } / \mathrm{V}_{\min }\right)$ & 1.64 \\
\cline { 3 - 4 } Cooling end chamber & 1.72 & Power Output $(\mathrm{W})$ & 33.4 \\
\cline { 3 - 5 } Clearance and Conduit & 1.28 & Specific Power $\left(\mathrm{W} / \mathrm{cm}^{3}\right)$ & 1.88 \\
\hline Mean Pressure $P_{\mathrm{m}}$ (bar) & 1.48 & Indicated Thermal Efficiency (\%) & 43.9 \\
\hline
\end{tabular}

\section{Optimization of porous-sheets regenerator and comparison with optimized wire mesh regenerator}

In this section, the authors evolve the regenerator optimization method originally presented by Hamaguchi etc. [26], which had been validated with real engine tests by Miyabe et al. [27], to further incorporate the total entropy generation rate into consideration. Given the same operating condition, the geometrical parameters of both porous sheets regenerator and conventional wire mesh regenerator can be optimized in terms of heat transfer characteristics, flow resistance and entropy generation rate, so the comprehensive performance of the two types of 
regenerators can be compared on an equal basis. The optimization procedure is briefly described as follows.

(1) Given the same combination of operating conditions, including the mean pressure $P_{\mathrm{m}}$, the hot and cold end temperature $T_{\mathrm{h}}$ and $T_{\mathrm{c}}$, the rotational velocity $n$ and the matrix diameter $\Phi$, calculate the thermal properties $\rho_{\mathrm{s}}$, $\rho_{\mathrm{f}}, \quad c_{\mathrm{p}, \mathrm{f}}, c_{\mathrm{s}}, k_{\mathrm{s}}, k_{\mathrm{f}}, \mu$, the mean mass flow rate $\dot{m}$, the mean fluid temperature $T_{\mathrm{fm}}$ and the blow time $t_{\text {blow }}$ for half cycle.

(2) Assume a mesh wire diameter, $d_{\mathrm{w}}$, then calculate Nusselt number, $\mathrm{Nu}$, Biot number, $\mathrm{Bi}$ and Fourier number, Fo.

$$
N u_{\mathrm{d}}=0.42 R e_{\mathrm{d}}^{0.56} \text {, for mesh wire [26] }
$$

$$
N u_{\mathrm{d}_{\mathrm{h}}}=5.3 \text {, for hexagonal porous sheets }
$$

where $N u_{\mathrm{d}}=h d_{\mathrm{w}} / k_{\mathrm{f}}, R e_{\mathrm{d}}=\rho_{\mathrm{f}} u_{\mathrm{m}} d_{\mathrm{w}} / \mu$, where $u_{\mathrm{m}}$ is the flow velocity within the matrix defined by $u_{\mathrm{m}}=u_{0} / \beta$, where $u_{0}$ is the frontal flow velocity, and $\beta=A_{\mathrm{f}} / A_{\mathrm{reg}}$ is ratio of the free flow area $A_{\mathrm{f}}$ to the frontal area $A_{\text {reg }}$. The Biot number is defined as $B i=h d_{\mathrm{w}} / 2 k_{\mathrm{w}}$ for mesh wire, and $B i=h \delta_{\mathrm{w}} / k_{\mathrm{w}}$ for porous sheets. The Fourier number is $F o=4 a_{\mathrm{w}} t_{\text {blow }} / d_{\mathrm{w}}{ }^{2}$ for mesh wire, and $F o=a_{\mathrm{w}} t_{\text {blow }} / \delta_{\mathrm{w}}{ }^{2}$ for porous sheets.

(3) Select an appropriate $d_{\mathrm{m}}$, to ensure $0.95 \leq\left.\Theta(B i, F o)\right|_{x=0, \text { or } r=0} \leq 1$ according to the following analytical solutions [28], where $\Theta=\left(T-T_{0}\right) /\left(T_{\mathrm{fm}}-T_{0}\right)$ is the dimensionless centerline temperature of the solid material (mesh wire or porous sheet), $T$ is the transient local solid temperature, $T_{\mathrm{fm}}$ is the mean flu id temperature and $T_{0}$ is the initial solid temperature.

$$
\left.\Theta\right|_{x=0, \text { or r }=0}=1-\sum_{\mathrm{n}=1}^{\infty} C_{\mathrm{n}} \exp \left(-\mu_{\mathrm{n}}^{2} F o\right)
$$

For porous sheets / parallel plates,

$$
C_{\mathrm{n}}=\frac{2 \sin \mu_{\mathrm{n}}}{\mu_{\mathrm{n}}+\cos \mu_{\mathrm{n}} \sin \mu_{\mathrm{n}}}
$$

where $\mu_{\mathrm{n}}$ is positive roots of the following transcendental equation.

$$
\mu_{\mathrm{n}} \tan \mu_{\mathrm{n}}=B i, \quad n=1,2, \cdots
$$


For cylindrical mesh wires,

$$
C_{\mathrm{n}}=\frac{2 \mathrm{~J}_{1}\left(\mu_{\mathrm{n}}\right)}{\mu_{\mathrm{n}}\left[\mathrm{J}_{0}^{2}\left(\mu_{\mathrm{n}}\right)+\mathrm{J}_{1}^{2}\left(\mu_{\mathrm{n}}\right)\right]}
$$

where $\mu_{\mathrm{n}}$ is positive roots of the following transcendental equation.

$$
\mu_{\mathrm{n}} \mathrm{J}_{1}\left(\mu_{\mathrm{n}}\right)=\operatorname{BiJ}_{0}\left(\mu_{\mathrm{n}}\right), \quad n=1,2, \cdots
$$

(4) Select number of layers for wire mesh or porous sheets, $N$ to satisfy $\varepsilon\left(N_{\mathrm{TU}}, C r\right) \geq 0.95$ according to the following analytical solution [26].

$$
\varepsilon=\frac{1}{N_{\mathrm{TU}}}\left\{N_{\mathrm{TU}}-\frac{N_{\mathrm{TU}}}{C r}-1+e^{-\left(N_{\mathrm{TU}}+\frac{N_{\mathrm{TU}}}{C r}\right)} I_{0}\left(\frac{2 N_{\mathrm{TU}}}{\sqrt{C r}}\right)+\int_{0}^{\frac{N_{\mathrm{TU}}}{C r}}\left(2+\frac{N_{\mathrm{TU}}}{C r}-z\right) e^{-\left(N_{\mathrm{TU}}+z\right)} I_{0}\left(2 \sqrt{N_{\mathrm{TU}} Z}\right) d z\right\}
$$

where $\varepsilon$ is the thermal effectiveness of the regenerator, $\varepsilon=\left(T_{\mathrm{fh}}-T_{\mathrm{fc}}\right) /\left(T_{\mathrm{mh}}-T_{\mathrm{fc}}\right)$, where $T_{\mathrm{fh}}$ and $T_{\mathrm{fc}}$ are hot and cold end fluid temperature, and $T_{\mathrm{mh}}$ is the hot end matrix temperature, $N_{\mathrm{TU}}$ is the number of heat transfer units, $N_{\mathrm{TU}}=(h S) /\left(\dot{m} c_{\mathrm{p}}\right)$, where $S$ is the total heat transfer area between solid matrix and fluid, $\dot{m}$ is the mean mass flow rate. $C r=M C_{\mathrm{m}} /\left(\dot{m} c_{\mathrm{p}} t_{\text {blow }}\right)$ is the heat capacity ratio of the solid matrix to the fluid flowing through the matrix.

(5) Readjust $N$ to minimize the total entropy generation rate, $\dot{S}_{\mathrm{g}}=\dot{S}_{\mathrm{g}, \mathrm{h}}+\dot{S}_{\mathrm{g}, \mathrm{f}}$, where $\dot{S}_{\mathrm{g}, \mathrm{h}}=Q\left|\frac{1}{T_{\mathrm{s}}}-\frac{1}{T_{\mathrm{f}}}\right| \approx Q \frac{\Delta T}{T_{\mathrm{f}}{ }^{2}}$ is the portion caused by the irreversible heat transfer between solid matrix and working fluid, where $Q$ is the total heat transfer between them, and $\Delta T=\left|T_{\mathrm{f}}-T_{\mathrm{s}}\right| ; \quad \dot{S}_{\mathrm{g}, \mathrm{f}}$ is caused by the flow friction. Also check that the flow frictional loss $(\Delta p)_{\mathrm{f}}$ is within acceptable range.

For a porous-sheets regenerator,

$$
\begin{gathered}
\Delta T=\frac{Q}{S} \frac{d_{\mathrm{h}}}{N u_{d_{\mathrm{h}}} k_{\mathrm{f}}} \\
\dot{S}_{\mathrm{g}, \mathrm{f}}=\frac{1}{2} \rho u_{\text {max }}^{2} C_{\mathrm{f}, \infty, \mathrm{ave}} S\left|u_{\mathrm{m}}\right| \frac{1}{T_{\mathrm{f}}} \\
(\Delta p)_{\mathrm{f}}=\frac{4 L}{\sqrt{3} a} C_{\mathrm{f}, \infty, \mathrm{ave}} \frac{1}{2} \rho u_{\text {max }}^{2}
\end{gathered}
$$

where $S$ is the total heat transfer area between matrix and fluid. 
For a wire mesh regenerator,

$$
\begin{gathered}
\Delta T=\frac{Q}{S} \frac{d_{\mathrm{w}}}{N u_{\mathrm{d}} k_{\mathrm{f}}} \\
\dot{S}_{\mathrm{g}, \mathrm{f}}=(\Delta p)_{\mathrm{f}} A_{0}\left|u_{0}\right| \frac{1}{T_{\mathrm{f}}} \\
(\Delta p)_{\mathrm{f}}=N \frac{1}{2} \rho u_{\mathrm{m}}{ }^{2} f
\end{gathered}
$$

where $N$ is the number of mesh screens, and $f$ is the flow friction coefficient given by the experimental correlation [27]

$$
f=\frac{33.6}{\operatorname{Re}_{l}}+0.337
$$

where $R e_{l}$ is defined by $\operatorname{Re}_{l}=\rho u_{\mathrm{m}} l / \mu$, where $l$ is the side length of the mesh aperture.

Table 2 The geometric parameters of optimized wire mesh [27].

\begin{tabular}{|c|c|c|c|c|c|c|}
\hline Mesh \# & $\begin{array}{c}d_{\mathrm{w}} \\
{[\mathrm{mm}]}\end{array}$ & $\begin{array}{c}p \\
{[\mathrm{~mm}]}\end{array}$ & $\begin{array}{c}l \\
{[\mathrm{~mm}]}\end{array}$ & $\beta$ & $\varphi$ & $\begin{array}{c}\sigma \\
{\left[\mathrm{mm}^{2} / \mathrm{mm}^{3}\right]}\end{array}$ \\
\hline 300 & 0.040 & 0.084 & 0.044 & 0.274 & 0.586 & 32.52 \\
\hline 200 & 0.050 & 0.127 & 0.077 & 0.368 & 0.668 & 21.72 \\
\hline 150 & 0.071 & 0.169 & 0.098 & 0.336 & 0.642 & 16.26 \\
\hline
\end{tabular}

Note: $p$ - pitch; $l$-Aperture side length; $\sigma$ - Specific surface area

Table 3 The geometric parameters of optimized porous sheets. Sheet thickness $\delta_{\mathrm{t}}=0.1 \mathrm{~mm}$.

\begin{tabular}{|c|c|c|c|c|}
\hline $\begin{array}{c}\text { Porous Sheet } \\
\text { Code \# }\end{array}$ & $\begin{array}{c}2 \delta_{\mathrm{w}} \\
{[\mathrm{mm}]}\end{array}$ & $\begin{array}{c}a \\
{[\mathrm{~mm}]}\end{array}$ & $\begin{array}{c}\beta=\phi \\
\left(a+\frac{2}{\sqrt{3}} \delta_{\mathrm{w}}\right)^{2}\end{array}$ & $\begin{array}{c}\sigma=\frac{4 a}{\sqrt{3}\left(a+\frac{2}{\sqrt{3}} \delta_{\mathrm{w}}\right)^{2}} \\
{\left[\mathrm{~mm}^{2} / \mathrm{mm}^{3}\right]}\end{array}$ \\
\hline $\mathrm{A}$ & 0.022 & 0.060 & 0.681 & 26.22 \\
\hline $\mathrm{B}$ & 0.048 & 0.075 & 0.533 & 16.42 \\
\hline $\mathrm{C}$ & 0.058 & 0.100 & 0.561 & 12.96 \\
\hline $\mathrm{D}$ & 0.024 & 0.100 & 0.771 & 17.81 \\
\hline
\end{tabular}

Note: $a$ - side length of the hexagonal cross section; $\delta_{\mathrm{w}}-$ wall thickness as denoted in Fig. 1(b).

Some typical operating conditions are selected for optimization according to the above procedure. The resulting optimum geometric parameters of wire mesh regenerators and porous-sheets regenerators are shown in 
Tables 2 and 3. The major operating parameters are compared in Table 4. It is found that under each operating condition, the porous-sheets regenerator has significantly lower flow frictional loss while keeping the same or higher thermal effectiveness, thus leading to significantly less total entropy generation rate (38\% 51\% less) in comparison with the corresponding wire mesh regenerator. Since the total entropy generation rate, $\dot{S}_{\mathrm{g}}$ is an indicator of available work loss, $W_{l}=T_{0} \dot{S}_{\mathrm{g}}$, where $T_{0}$ is the absolute ambient temperature, it can be reasonably used to measure the work loss within the regenerator caused by irreversible heat transfer and flow friction, therefore it should be minimized in the engine design in order to obtain maximum power output and thermal efficiency.

Table 4 Comparis on between optimized porous-sheets regenerator and optimized wire mesh regenerator based on minimization of total entropy generation rate. $\left(T_{\mathrm{C}}=400 \mathrm{~K}, T_{\mathrm{e}}=900 \mathrm{~K}\right)$.

\begin{tabular}{|c|c|c|c|c|c|c|c|c|}
\hline $\begin{array}{l}\text { Operating } \\
\text { condition }\end{array}$ & \multicolumn{2}{|c|}{$\begin{array}{l}\mathrm{P}_{\mathrm{m}}=1.879 \mathrm{MPa} \\
n=2600 \mathrm{rpm} \\
\Phi=28.8 \mathrm{~mm}\end{array}$} & \multicolumn{2}{|c|}{$\begin{array}{l}\mathrm{P}_{\mathrm{m}}=1.957 \mathrm{MPa} \\
n=1000 \mathrm{rpm} \\
\Phi=28.8 \mathrm{~mm}\end{array}$} & \multicolumn{2}{|c|}{$\begin{array}{l}\mathrm{P}_{\mathrm{m}}=3.132 \mathrm{MPa} \\
n=600 \mathrm{rpm} \\
\Phi=28.8 \mathrm{~mm}\end{array}$} & \multicolumn{2}{|c|}{$\begin{array}{l}\mathrm{P}_{\mathrm{m}}=1.253 \mathrm{MPa} \\
n=1200 \mathrm{rpm} \\
\Phi=14.0 \mathrm{~mm}\end{array}$} \\
\hline $\begin{array}{c}\text { Regenerator } \\
\text { element }\end{array}$ & $\begin{array}{l}\text { Wire } \\
\text { mesh } \\
\text { M300 }\end{array}$ & $\begin{array}{c}\text { Porous } \\
\text { Sheet } \\
\text { A } \\
\end{array}$ & $\begin{array}{l}\text { Wire } \\
\text { mesh } \\
\text { M200 }\end{array}$ & $\begin{array}{c}\text { Porous } \\
\text { Sheet } \\
\text { B } \\
\end{array}$ & $\begin{array}{l}\text { Wire } \\
\text { mesh } \\
\text { M150 }\end{array}$ & $\begin{array}{c}\text { Porous } \\
\text { Sheet } \\
\text { C } \\
\end{array}$ & $\begin{array}{l}\text { Wire } \\
\text { mesh } \\
\text { M150 }\end{array}$ & $\begin{array}{c}\text { Porous } \\
\text { Sheet } \\
\text { D } \\
\end{array}$ \\
\hline$B i$ & 0.0117 & 0.00709 & 0.00672 & 0.0124 & 0.00841 & 0.0112 & 0.0167 & 0.00387 \\
\hline Fo & 134.6 & 444.9 & 223.9 & 243.0 & 185.1 & 277.3 & 92.5 & 809.9 \\
\hline $\operatorname{Tr}$ & 0.956 & 0.957 & 0.950 & 0.950 & 0.955 & 0.955 & 0.953 & 0.956 \\
\hline $\mathrm{Cr}$ & 80.4 & 141.0 & 206.0 & 323.2 & 347.3 & 540.4 & 52.3 & 72.8 \\
\hline$N_{\mathrm{TU}}$ & 200.0 & 405.5 & 511.2 & 826.9 & 878.8 & 1451.4 & 131.0 & 214.9 \\
\hline$N$ & 107 & 195 & 285 & 318 & 502 & 905 & 128 & 396 \\
\hline$\varepsilon$ & 0.982 & 0.990 & 0.993 & 0.997 & 0.998 & 0.999 & 0.973 & 0.982 \\
\hline$(\Delta p)_{\mathrm{f}}(\mathrm{kPa})$ & 13.86 & 6.822 & 5.651 & 3.498 & 5.269 & 3.192 & 14.03 & 8.601 \\
\hline$\dot{S}_{\mathrm{g}}(\mathrm{W} / \mathrm{K})$ & 0.0657 & 0.0324 & 0.0103 & 0.0064 & 0.0058 & 0.0035 & 0.0308 & 0.0188 \\
\hline
\end{tabular}

Note: $\mathrm{P}_{\mathrm{m}}$ - Mean operating pressure; $n$-Rotational speed; $\Phi$ - Matrix diameter.

The step (5) of the above optimization procedure is based on minimization of total entropy generation rate, then the resulted dead volume may be different for the two kinds of regenerator. If the number of matrix layers, $\mathrm{N}$ is selected to let the two kinds of regenerator have equal dead volumes while assuming all the same operating 
conditions as in Table 4, the resulted thermal effectiveness, pressure drop and total entropy generation rates are compared in Table 5. It can be found that the total entropy generation rates of the porous-sheets regenerator only amount to $34.8 \% \sim 65.8 \%$ of that of the corresponding wire mesh regenerator. In other words, the frictional pressure drop through the porous-sheets regenerator only amounts to a small fraction $(18.6 \% \sim 69.5 \%)$ of that of the corresponding wire mesh regenerator while keeping similar thermal effectiveness.

Table 5 Comparison between porous-sheets regenerator and wire mesh regenerator based on equal dead volume. ( $T_{\mathrm{c}}$

\begin{tabular}{|c|c|c|c|c|c|c|c|c|}
\hline $\begin{array}{l}\text { Operating } \\
\text { condition }\end{array}$ & \multicolumn{2}{|c|}{$\begin{array}{l}\mathrm{P}_{\mathrm{m}}=1.879 \mathrm{MPa} \\
n=2600 \mathrm{rpm} \\
\Phi=28.8 \mathrm{~mm}\end{array}$} & \multicolumn{2}{|c|}{$\begin{array}{l}\mathrm{P}_{\mathrm{m}}=1.957 \mathrm{MPa} \\
n=1000 \mathrm{rpm} \\
\Phi=28.8 \mathrm{~mm}\end{array}$} & \multicolumn{2}{|c|}{$\begin{array}{l}\mathrm{P}_{\mathrm{m}}=3.132 \mathrm{MPa} \\
n=600 \mathrm{rpm} \\
\Phi=28.8 \mathrm{~mm}\end{array}$} & \multicolumn{2}{|c|}{$\begin{array}{l}\mathrm{P}_{\mathrm{m}}=1.253 \mathrm{MPa} \\
n=1200 \mathrm{rpm} \\
\Phi=14.0 \mathrm{~mm}\end{array}$} \\
\hline $\begin{array}{l}\text { Regenerator } \\
\text { element }\end{array}$ & $\begin{array}{l}\text { Wire } \\
\text { mesh } \\
\text { M300 }\end{array}$ & $\begin{array}{c}\text { Porous } \\
\text { Sheet } \\
\text { A }\end{array}$ & $\begin{array}{l}\text { Wire } \\
\text { mesh } \\
\text { M200 }\end{array}$ & $\begin{array}{c}\text { Porous } \\
\text { Sheet } \\
\text { B }\end{array}$ & $\begin{array}{l}\text { Wire } \\
\text { mesh } \\
\text { M150 }\end{array}$ & $\begin{array}{l}\text { Porous } \\
\text { Sheet } \\
\text { C }\end{array}$ & $\begin{array}{l}\text { Wire } \\
\text { mesh } \\
\text { M150 }\end{array}$ & $\begin{array}{c}\text { Porous } \\
\text { Sheet } \\
\text { D }\end{array}$ \\
\hline$V_{\mathrm{D}, \mathrm{R}}\left(\mathrm{cm}^{3}\right)$ & \multicolumn{2}{|c|}{7.45} & \multicolumn{2}{|c|}{8.61} & \multicolumn{2}{|c|}{10.97} & \multicolumn{2}{|c|}{5.98} \\
\hline$V_{\mathrm{D}, \mathrm{T}}\left(\mathrm{cm}^{3}\right)$ & \multicolumn{2}{|c|}{12.17} & \multicolumn{2}{|c|}{13.33} & \multicolumn{2}{|c|}{15.69} & \multicolumn{2}{|c|}{10.69} \\
\hline$N$ & 244 & 168 & 198 & 248 & 185 & 300 & 426 & 503 \\
\hline$\varepsilon$ & 0.990 & 0.988 & 0.988 & 0.993 & 0.987 & 0.990 & 0.989 & 0.985 \\
\hline$(\Delta p)_{\mathrm{f}}(\mathrm{kPa})$ & 31.59 & 5.877 & 3.926 & 2.728 & 1.942 & 1.058 & 46.69 & 10.92 \\
\hline$\dot{S}_{\mathrm{g}}(\mathrm{W} / \mathrm{K})$ & 0.0892 & 0.0327 & 0.0110 & 0.0066 & 0.0089 & 0.0058 & 0.0557 & 0.0194 \\
\hline
\end{tabular}

Note: $V_{\mathrm{D}, \mathrm{T}}-$ Total dead volume; $V_{\mathrm{D}, \mathrm{R}}-$ Regenerator dead volume.

\section{Conclusion}

In this study, the reciprocating flow and heat transfer characteristics in a model Stirling engine with a compact porous-sheets heat exchanger are numerically simulated by a dynamic mesh CFD method and are validated with analytical solutions and experimental results. The following major conclusions can be drawn from the analysis.

(1) The flow frictional loss in the porous-sheets regenerator with regular shaped flow channels under the working condition of 1 atm and 2,600 rpm can be as low as $800 \mathrm{~Pa}$. 
(2) Although the local heat transfer coefficient varies largely in the longitudinal direction due to the strong dependence of gas thermal conductivity on temperature, the local Nusselt number varies less than $3.7 \%$ and shows a valley-shaped pattern in the longitudinal direction. The Nusselt number varies less than $1.4 \%$ with crank angles. A spatial-temporally averaged Nusselt number of 5.33 for the case of constant heater wall heat flux, and 5.31 for the case of constant heater wall temperature are obtained respectively, which are somewhat higher than the analytical values of 4.00 and 3.34 for fully developed unidirectional la minar flow in a long pipe with hexagonal shaped cross section.

(3) A calculated power of $33.4 \mathrm{~W}$, corresponding to a specific power of $1.88 \mathrm{~W} / \mathrm{cm}^{3}$ based on the swept volume of the expansion cylinder, and an indicated thermal efficiency of $43.9 \%$ is obtained. The high performance of the model Stirling engine can be attributed to the low frictional loss and the excellent heat transfer characteristics, as well as the compact heat exchanger design that significantly reduces the dead volume.

(4) Optimization of both the porous sheets regenerator and the conventional wire mesh regenerator shows that under given operating conditions, the porous-sheets regenerator has 38\% 51\% lower total entropy generation rate while maintaining the same or higher thermal effectiveness, thus leading to less available work loss, contributing to higher power output and thermal efficiency.

\section{Acknowledgement}

The authors gratefully acknowledge the financial support from the NSFC-JST "Strategic China-Japan Cooperative Program” under Grant No. 51161140332. The authors would also express their gratitude to Mr. Fukui of the Fujifilm Co. Ltd., the designer of the porous-sheets regenerator in this research.

\section{References}

[1] Organ AJ. The air engine - Stirling cycle power for a sustainable future. Cambridge (Britain): Woodhead; 
2007.

[2] Organ AJ. The regenerator and the Stirling engine. London (Britain): Mechanical Engineering Publications; 1997.

[3] Tew R, Ibrahim M, Danila D, Simon T, Mantell S, Sun L, Gedeon D, Kelly K, McLean J, Wood G, Qiu S. A microfabricated involute-foil regenerator for Stirling engines. Cleveland, Ohio (US): National Aeronautics and Space Administration; 2007 Oct. Report No.: NASA/TM-2007-214973.

[4] Rulich I, Quack H. Investigations on regenerative heat exchangers. Cryocoolers. 1999; 10: 265-74.

[5] Ibrahim MB, Gedeon D, Wood G, McLean J. A microfabricated segmented-involute-foil regenerator for enhancing reliability and performance of Stirling engines. Cleveland, Ohio (US): National Aeronautics and Space Administration; 2009 Jun. Report No.: NASA/CR-2009-215516.

[6] Ibrahim M, Simon T, Mantell S, Gedeon D, Qiu S, Wood G, Kelly K, McLean J. A microfabricated segmented-involute-foil regenerator for enhancing reliability and performance of Stirling engines. Cleveland, Ohio (US): National Aeronautics and Space Administration; 2007 Dec. Report No.: NASA/CR-2007-215006.

[7] Takizawa H, Kitahama D, Kagawa N, Matsuguchi A, Tsuruno S. Development of new matrix material for Stirling engine regenerator. Trans JSME B. 2004; 70: 823-8.

[8] Matsuguchi A, Kagawa N, Koyama S. New matrix for Stirling engine regenerator (Design of regenerator using mesh sheet). Design Engineering. 2011; 46: 22-8 (In Japanese).

[9] Nam K, Jeong S. Development of parallel wire regenerator for cryocoolers. Cryogenics, 2006; 46: 278-87.

[10] Martini WR. Stirling engine design manual, 2nd. Ed. Richland (US): Martini Engineering; 1983 Jan. Report No.: CR-168088.

[11] Cheng CH, Yang HS. Analytical model for predicting the effect of operating speed on shaft power output of Stirling engines. Energy. 2011; 36: 5899-908. 
[12] Cheng CH, Yang HS, Theoretical model for predicting thermodynamic behavior of thermal-lag Stirling engine. Energy. 2013; 49: 218-28.

[13] Rogdakis ED, Antonakos GD, Koronaki IP. Thermodynamic analysis and experimental investigation of a Solo V161 Stirling cogeneration unit. Energy. 2012; 45: 503-11

[14] Campos MC, Vargas JVC, Ordonez JC. Thermodynamic optimization of a Stirling engine. Energy. 2012; 44: 902-10.

[15] Mahkamov K. Design improvements to a biomass Stirling engine using mathematical analysis and 3D CFD modeling. J Energy Resour Technol. 2006; 128: 203-15.

[16] Mahkamov K. An axisymmetric co mputational fluid dynamics approach to the analysis of the working process of a solar Stirling engine. J Sol Energy Eng. 2006; 128: 45-53.

[17] Zink F, Vipperman J, Schaefer L. CFD simulation of a thermoacoustic engine with coiled resonator. Int Comm Heat Mass Transf. 2010; 37: 226-9.

[18] Antao DS, Farouk B. Computational fluid dynamics simulations of an orifice type pulse tube refrigerator: effects of operating frequency. Cryogenics. 2011; 51: 192-201.

[19] Costa SC, Barrutia H, Esnaola JA, Tutar M. Numerical study of the pressure drop phenomena in wound woven wire matrix of a Stirling regenerator. Energy Conversion and Management. 2013; 67: 57-65.

[20] Geocities.jp [Internet]. [updated 2013 Sept. 15; cited 2013 Sept. 16]. Available from: www.geocities.jp/takashdc4/tf2rm14/tomcat10_drawings.pdf.

[21] ANSYS, Inc. ANSYS FLUENT User's Guide Release 14.0; Canonsburg (US); 2011 (CD-ROM).

[22] Zhao TS, Cheng P. Experimental studies on the onset of turbulence and frictional losses in an oscillatory turbulent pipe flow. Int J Heat Fluid Flow. 1996; 17: 356-62.

[23] Uchida S. The pulsating viscous flow superposed on the steady laminar motion of incompressible fluid in a 
circular pipe. ZAMP. 1956; 7: 403-22.

[24] Zhao TS, Cheng P. The friction coefficient of a fully developed laminar reciprocating flow in a circular pipe. Int J Heat Fluid Flow. 1996; 17: 167-72.

[25] Rohsenow WM, Hartnett JR, Cho YI. Handbook of heat transfer, 3rd ed. New York (US): Mcgraw-Hill; 1998.

[26] Hamaguchi K, Takahashi S, Miyabe H. Heat Transfer characteristics of a regenerator matrix: case of packed wire gauzes. Trans JSME B. 1983; 49 (445): 2001-10 [in Japanese].

[27] Miyabe H, Takahashi S, Hamaguchi K. An approach to the design of Stirling engine regenerator matrix using packs of wire gauzes. In: Proc. 17th IECEC; 1982 Aug 8; Los Angeles, CA, US; p. 1839-44.

[28] Özışik M N. Heat conduction. New York (US): John Wiley and Sons; 1980. 